\title{
Nonlinear Behaviour of Concrete Buttress Dams under High-Frequency Excitations Taking into Account Topographical Amplifications
}

\author{
Roghayeh Abbasiverki $\left(\mathbb{D}\right.$, Richard Malm $\mathbb{D}^{D}$, Anders Ansell $(\mathbb{D}$, and Erik Nordström \\ Division of Concrete Structures, KTH Royal Institute of Technology, Stockholm SE-100 44, Sweden \\ Correspondence should be addressed to Roghayeh Abbasiverki; roghayeh.abbasiverki@byv.kth.se
}

Received 17 September 2021; Revised 21 October 2021; Accepted 22 October 2021; Published 11 November 2021

Academic Editor: P. Antonaci

Copyright ( 2021 Roghayeh Abbasiverki et al. This is an open access article distributed under the Creative Commons Attribution License, which permits unrestricted use, distribution, and reproduction in any medium, provided the original work is properly cited.

\begin{abstract}
Concrete buttress dams could potentially be susceptible to high-frequency vibrations, especially in the cross-stream direction, due to their slender design. Previous studies have mainly focused on low-frequency vibrations in stream direction using a simplified foundation model with the massless method, which does not consider topographic amplifications. This paper therefore investigates the nonlinear behaviour of concrete buttress dams subjected to high-frequency excitations, considering cross-stream vibrations. For comparison, the effect of low-frequency excitations is also investigated. The influence of the irregular topography of the foundation surface on the amplification of seismic waves at the foundation surface and thus in the dam is considered by a rigorous method based on the domain-reduction method using the direct finite element method. The sensitivity of the calculated response of the dam to the free-field modelling approach is investigated by comparing the result with analyses using an analytical method based on one-dimensional wave propagation theory and a massless approach. Available deconvolution software is based on the one-dimensional shear wave propagation to transform the earthquake motion from the foundation surface to the corresponding input motion at depth. Here, a new deconvolution method for both shear and pressure wave propagation is developed based on an iterative time-domain procedure using a one-dimensional finite element column. The examples presented showed that topographic amplifications of high-frequency excitations have a significant impact on the response of this type of dam. Cross-stream vibrations reduced the safety of the dam due to the opening of the joints and the increasing stresses. The foundation modelling approach had a significant impact on the calculated response of the dam. The massless method produced unreliable results, especially for high-frequency excitations. The free-field modelling with the analytical method led to unreliable joint openings. It is therefore recommended to use an accurate approach for foundation modelling, especially in cases where nonlinearity is considered.
\end{abstract}

\section{Introduction}

Seismic evaluation of concrete dams is essential because of the catastrophic consequences in case of their failure. Evaluation of buttress dams requires special attention, especially in areas of hard rock where seismic excitations are dominated by highfrequency vibrations. To increase efficiency, concrete buttress dams have a much lower mass than, for example, a corresponding massive gravity dam. Both the front-plate and the supporting buttresses are relatively slender, but due to their design the stiffness of a monolith is quite high, resulting in high natural vibration frequencies of the dams and low resistance to cross-stream vibrations. Another factor that can have a significant influence on the response of concrete buttresses is topographical amplification due to high-frequency ground motions at the interface between the dam and the foundation. In addition, concrete buttress dams are designed as individual monoliths separated by vertical contraction joints that are expected to open/close and slide cyclically when subjected to strong earthquake ground motions. Therefore, it is important to study the seismic response of such structures, especially in the cross-stream direction. 
Concrete buttress dams have shown their vulnerability to nearby earthquakes. Examples of two buttress dams shaken by significant earthquakes are the Hsinfengkiang dam in China during the 1962 earthquake and the Sefid-rud dam in Iran during the 1990 Manjil earthquake $[1,2]$. The limited discussion found in the literature on the dynamic behaviour of buttress dams mainly focus on the behaviour in the stream directions. Ghaemmaghami and Ghaemian [3] performed experimental seismic investigation of the Sefid-rud concrete buttress dam using a model on a shaking table. They investigated nonlinear seismic response of the highest monolith with a case of an empty reservoir. The model was excited only in the longitudinal and transverse directions (no vertical component). The transverse acceleration was reduced by $10 \%$ to compensate for the absence of lateral supports in the dam. Ilinca et al. [4] conducted seismic analysis for one monolith of a buttress dam, using the spectral analysis and the direct time integration methods. An accelerogram was applied, in the upstream-downstream direction. The hydrodynamic effect of the reservoir was considered according to the added mass procedure. Hariri-Ardebili and Seyed-Kolbadi [5] modelled one monolith of the Sefid-rud dam. Pressure-based fluid elements were used for modelling the reservoir domain with a massless approach for the foundation. All three components of the Manjil earthquake were applied to the finite element model but the dam was restricted to in-plane vibrations only. Colombo et al. [6] studied the bearable maximum seismic action of concrete buttress dams while considering the sliding in the construction and foundation. They used a pseudo-static analysis of a concrete buttress dam monolith with constraining lateral movement of the monolith [7] and developed a method to validate finite element modelling of concrete buttress dams [8]. Chi-fai et al. [9] performed a response spectrum and linear time history analysis using a threedimensional finite element model of the Oberon buttress dam located in the Central Tablelands region of New South Wales, Australia, with a $232 \mathrm{~m}$ long concrete buttress section with a maximum height of $35 \mathrm{~m}$. Hydrodynamic pressure was included by using the added mass method and the rock foundation was modelled by the massless method. The fundamental mode shape of the buttress dam model show in-phase vibrations of some of the buttresses with a relatively high frequency of $11.93 \mathrm{~Hz}$, which should be compared to the predominant frequency of the seismic load close to $5 \mathrm{~Hz}$.

The critical factors that have a significant effect on the seismic response of dams are water compressibility in damreservoir interaction, radiation damping in infinite foundation, variation of seismic input at dam foundation interfaces, and nonlinear behaviour of the dam and foundation. To facilitate nonlinear dynamic analysis, the most common approximation is by applying the massless foundation method proposed by Clough [10]. Chopra [11] showed that this method is unrealistic. There are two limitations for the massless method: (1) ignoring the radiation damping effect of the infinite foundation and (2) ignoring topographic amplifications. To overcome these limitations, a foundation mass should be defined with appropriate absorbing boundary conditions. Bielak et al. [12] proposed a two-step finite element procedure called the domain-reduction method (DRM). In this, the effects of incoming waves due to remote excitations are introduced by equivalent nodal forces applied in a single continuous layer of elements in the interior of the truncated boundary. The rigorous procedure for free-field foundation modelling is based on using perfectly matched layers (PML) as absorbing boundary and DRM for the earthquake input mechanism $[13,14]$. The PML boundary and the DRM procedure are currently not available in most commercial FE codes; the only exception is LS-DYNA [15]. To overcome this, Lokke and Chopra [16] developed a method based on DRM, using the direct finite element (FE) method for viscous boundaries. In this method, effective earthquake forces are applied at nonreflecting boundaries. The effective earthquake forces at such boundaries can be computed through an analytical approach using one-dimensional (1D) wave theory. This method was developed for viscous-spring boundaries [17-19]. Then, Song et al. [20] developed this further for use with infinite element.

In this paper, the nonlinear behaviour of a typical concrete buttress dam under high-frequency seismic excitations is investigated. For comparison, the behaviour under low-frequency excitations is also analyzed. The behaviour of buttress dams, both in the stream and cross-stream directions, is investigated using three-dimensional finite element modelling. Topographic amplifications are considered using the direct finite element method (FE) (Lokke and Chopra [16]) and the analytical approach (Song et al. [20]). The results are also compared with those of the massless method. A deconvolution to transform the earthquake motion from the foundation surface to the corresponding input motion at depth is performed with a new time-domain deconvolution method for both shear and pressure wave propagation based on an iterative procedure using a one-dimensional FE column.

\section{Dam-Reservoir-Foundation System}

Interaction between reservoir, dam, and rock foundation during seismic excitation produces a hydrodynamic pressure. A simplified method for considering this pressure is the added mass approach [21, 22]. In this method, water compressibility is neglected, which results in unreliable seismic response in analyzed dams [23]. For considering the water compressibility, an acoustic fluid method can be used for numerical modelling of the reservoir in dam-water-foundation systems [24-26]. The acoustic wave equation can be used for simulating fluidstructure interaction by assuming that the fluid is compressible, irrotational, neglecting its viscosity, assuming no mean flow of the fluid and no body forces. The acoustic elements have only one degree of freedom, describing the pressure. In the dam-rock-reservoir system, acceleration of the boundaries in contact with the reservoir induces hydrodynamic pressures. Figure 1 illustrates different conditions at the reservoir boundaries.

In the FE discretization, the coupled equation of the dam-rock-reservoir system with truncated fluid and foundation domains is given by 


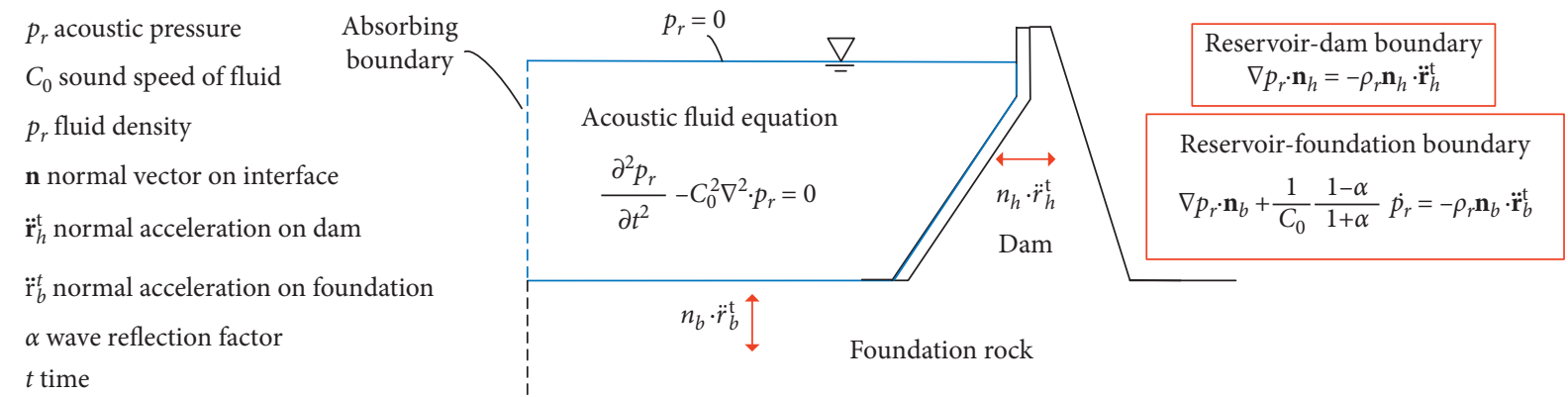

FIGURE 1: Schematic view of the dam-rock-reservoir FE model, highlighting the different conditions at the reservoir boundaries.

$$
\begin{array}{r}
{\left[\begin{array}{cc}
\mathbf{m} & 0 \\
\rho_{r}\left(\mathbf{Q}_{h}^{T}+\mathbf{Q}_{b}^{T}\right) & \mathbf{s}
\end{array}\right]\left\{\ddot{r}^{t} \ddot{p}_{r}^{t}\right\}+\left[\begin{array}{cc}
\mathbf{c}+\mathbf{c}_{f} & 0 \\
0 & \mathbf{b}+\mathbf{c}_{r}
\end{array}\right]\left\{\begin{array}{c}
\dot{r}^{t} \\
\dot{p}_{r}^{t}
\end{array}\right\}+\left[\begin{array}{cc}
\mathbf{k} & -\left(\mathbf{Q}_{h}+\mathbf{Q}_{b}\right) \\
0 & \mathbf{h}
\end{array}\right]\left\{\begin{array}{c}
\mathbf{r}^{t} \\
\mathbf{p}_{r}{ }^{t}
\end{array}\right\}=\left\{\begin{array}{c}
\mathbf{P}_{f}^{0} \\
0
\end{array}\right\},} \\
\mathbf{P}_{f}^{0}=2 \mathbf{c}_{f} \dot{r}_{I}^{0},
\end{array}
$$

where $\mathbf{m}, \mathbf{k}$, and $\mathbf{c}$ are the standard mass, stiffness, and damping matrices, respectively, for the dam-foundation system; $\mathbf{s}, \mathbf{b}$, and $\mathbf{h}$ are the mass, damping, and stiffness matrices, respectively, for the water; $\boldsymbol{c}_{f}$ and $\boldsymbol{c}_{r}$ are the damper matrixes at nonreflecting boundaries of the foundation and reservoir, respectively; $\mathbf{r}^{t}$ is the total displacements vector in the dam and rock foundation; and $\mathbf{p}_{r}^{t}$ the total hydrodynamic pressures vector in the fluid. $\mathbf{Q}_{b}$ and $\mathbf{Q}_{h}$ are matrices that couple accelerations to hydrodynamic pressures at the water-foundation rock interface and the dam-water interface, respectively. $\mathbf{P}_{f}^{0}$ is the effective earthquake forces associated with the absorbing boundaries of the foundation.

\section{Effective Earthquake Forces}

Two methods for computing effective earthquake forces which are implemented in this paper are described. These are both based on the assumption of vertical propagation of seismic waves.

3.1. Direct FE Method. Here, the free-field modelling of the foundation proposed by Lokke and Chopra [16] is considered as the reference solution. This method is accurate for seismic analysis of concrete dams. The application of this method was validated for the Morrow Point arch dam. In this method, the effective earthquake forces are obtained based on the scattering problem in which the dam perturbs the free-field motion in the unbounded media. In the direct FE method, the effective earthquake forces at the side foundation boundaries are obtained by

$$
\mathbf{P}_{f}^{0}=\mathbf{R}^{0}+\mathbf{c}_{f} \dot{r}^{0} .
$$

The effective earthquake forces consists of two parts: the forces $\mathbf{R}^{0}$ which are consistent with the free-field tractions at boundaries, and $\mathbf{c}_{f} \dot{r}^{0}$, the damper forces determined from the spatially varying free-field motion at the boundaries' nodes, where the free-field displacements are denoted by $\mathbf{r}^{0}$. Effective earthquake forces at the bottom boundary are computed by where $\dot{r}_{I}^{0}$ is the incident (upward propagating) seismic waves. The incident motion is computed as $1 / 2$ of the outcrop motion at the bottom boundary. Free-field motions $\dot{r}^{0}$ and tractions $\mathbf{R}^{0}$ at each nodal point are computed through auxiliary analyses. The free-field system shown in Figure 2(a) is reduced to a twodimensional free-field system with corresponding 1D corner columns, as in Figure 2(b). The effective earthquake forces at every node along the side boundaries are computed from equation (2), where $\dot{r}^{0}$ and $\mathbf{R}^{0}$ are determined from analyses of a $1 \mathrm{D}$ column assumed at the along-canyon boundaries. Free-field motions $\dot{r}^{0}$ and tractions $\mathbf{R}^{0}$ at the cross-canyon boundaries at the upstream and downstream ends of the domain are determined from analysis of the $2 \mathrm{D}$ system.

3.2. Analytical Method. In this method, the effective nodal forces are computed from

$$
\mathbf{F}_{f}=\mathbf{c}_{f} \dot{u}_{f}^{0}+\boldsymbol{\sigma}_{f}^{0} \mathbf{n},
$$

where $\dot{u}_{f}^{0}$ is the free-field velocity and $\sigma_{f}^{0}$ the free-field stress and $\mathbf{n}$ cosine vectors of the outer normal direction of the artificial boundary. The components of the free-field stress are obtained from the elastic theory:

$$
\left\{\begin{array}{c}
\sigma_{x x} \\
\sigma_{y y} \\
\sigma_{z z} \\
\sigma_{x y} \\
\sigma_{y z} \\
\sigma_{z x}
\end{array}\right\}=\left[\begin{array}{cccccc}
\lambda+2 G & \lambda & \lambda & 0 & 0 & 0 \\
\lambda & \lambda+2 G & \lambda & 0 & 0 & 0 \\
\lambda & \lambda & \lambda+2 G & 0 & 0 & 0 \\
0 & 0 & 0 & G & 0 & 0 \\
0 & 0 & 0 & 0 & G & 0 \\
0 & 0 & 0 & 0 & 0 & G
\end{array}\right]\left\{\begin{array}{c}
\frac{\partial u}{\partial x} \\
\frac{\partial v}{\partial y} \\
\frac{\partial w}{\partial z} \\
\frac{\partial u}{\partial z}+\frac{\partial v}{\partial x}+\frac{\partial w}{\partial y} \\
\frac{\partial w}{\partial x}+\frac{\partial u}{\partial z}
\end{array}\right\},
$$


where $[u v m]^{T}$ denotes the displacement vector and $\lambda$ and $G$ are the medium's Lame's constants. When a P-wave propagates vertically from the bottom boundary, the displacements of the incidental wave are $u=0, v=0, w$ $=w_{0}(t)$. The free-field displacement, velocity, and the partial derivative of the displacement at height $h$ are determined from the $1 \mathrm{D}$ wave motion theory in two parts, the incident and reflected waves:

$$
\left\{\begin{array}{l}
w=w_{0}\left(t-\frac{h}{c_{p}}\right)+w_{0}\left(t-\frac{2 H-h}{c_{p}}\right), \\
\dot{w}=\dot{w}_{0}\left(t-\frac{h}{c_{p}}\right)+\dot{w}_{0}\left(t-\frac{2 H-h}{c_{p}}\right), \\
\frac{\partial w}{\partial z}=-\frac{1}{c_{p}}\left[\dot{w}_{0}\left(t-\frac{h}{c_{p}}\right)-\dot{w}_{0}\left(t-\frac{2 H-h}{c_{p}}\right)\right],
\end{array}\right.
$$

where $H$ is the distance from the bottom boundary to the free surface. Using equations (5) and (6) and taking into account the conditions $u=0, v=0, h=0$ at the bottom boundary, the free-field stress is calculated as

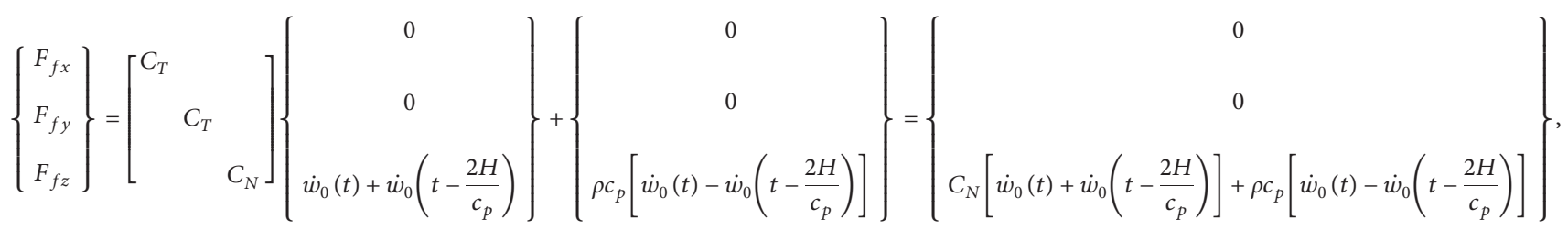

where $C_{T}=\rho c_{s}$ and $C_{N}=\rho c_{p}$ are the normal and tangential damping coefficients, respectively, and $\rho$ is the medium's mass density. Also, $c_{s}$ and $c_{p}$ are the wave velocities of the $\mathrm{S}$ - and $\mathrm{P}$-waves, respectively. When the shear wave propagates vertically from the bottom boundary, the particle displacements within the input wave are $u=u_{0}(t), v=0, w=0$, and the effective forces are derived by the analogous method:

$$
\left\{\begin{array}{c}
F_{f x} \\
F_{f y} \\
F_{f z}
\end{array}\right\}=\left\{\begin{array}{c}
C_{T}\left[\dot{u}_{0}(t)+\dot{u}_{0}\left(t-\frac{2 H}{c_{s}}\right)\right]+\rho c_{s}\left[\dot{u}_{0}(t)-\dot{u}_{0}\left(t-\frac{2 H}{c_{s}}\right)\right] \\
0 \\
0
\end{array}\right\} .
$$

The corresponding effective forces at four lateral boundaries are derived by the described procedure.

$$
\left\{\begin{array}{c}
\sigma_{x x} \\
\sigma_{y y} \\
\sigma_{z z} \\
\sigma_{x y} \\
\sigma_{y z} \\
\sigma_{z x}
\end{array}\right\}=\left\{\begin{array}{c}
\lambda \frac{\partial w}{\partial z} \\
\rho c_{p}^{2} \frac{\partial w}{\partial z} \\
0 \\
0
\end{array}\right\}=\left\{\begin{array}{c}
-\frac{\lambda}{c_{p}}\left[\dot{w}_{0}(t)-\dot{w}_{0}\left(t-\frac{2 H}{c_{p}}\right)\right] \\
-\frac{\lambda}{c_{p}}\left[\dot{w}_{0}(t)-\dot{w}_{0}\left(t-\frac{2 H}{c_{p}}\right)\right] \\
-\rho c_{p}\left[\dot{w}_{0}(t)-\dot{w}_{0}\left(t-\frac{2 H}{c_{p}}\right)\right] \\
0 \\
0 \\
0
\end{array}\right\} .
$$

Substituting equation (7) into (4) and taking into account the boundary condition $n=\left[\begin{array}{ccc}0 & 0 & -1\end{array}\right]^{T}$, the effective earthquake force in each direction at the bottom boundary are expressed as

\section{Concrete Buttress Dam Geometry and Material Properties}

The concrete buttress investigated in this study is chosen because its geometry and dimensions are representative of typical large concrete buttress dams in Sweden, where there are about 25 concrete buttress dams with similar geometry [27]. It is about $100 \mathrm{~m}$ long and consists of 13 almost identical concrete monoliths. A principal drawing of the studied monolith is shown in Figure 3. The monoliths are divided by vertical contraction joints, built with a waterstop. Each monolith consists of a $2 \mathrm{~m}$ thick and $8 \mathrm{~m}$ wide front-plate facing the water and a $40 \mathrm{~m}$ high supporting buttress that is $2 \mathrm{~m}$ thick and $34 \mathrm{~m}$ wide near the bedrock. The upper $10 \mathrm{~m}$ of the front-plate is vertical while the lower part is inclined, with an angle of $56.3^{\circ}$ versus the horizontal axis. The downstream edge of the buttress slopes $68.2^{\circ}$ versus the horizontal. The dam crest, the horizontal upper part of the buttress and front-plate, has a width of $4.5 \mathrm{~m}$. There is an 


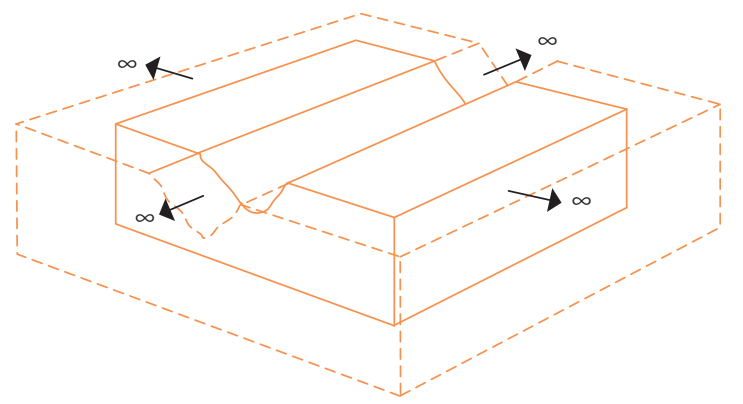

(a)

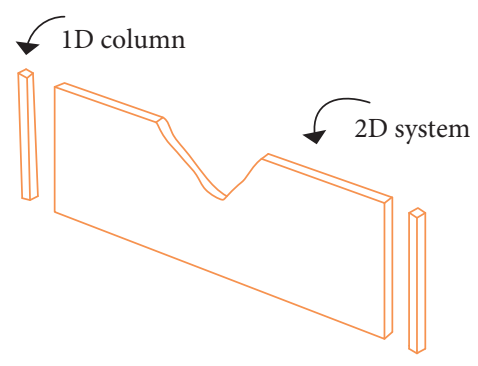

(b)

Figure 2: Computing effective earthquake forces with the direct FE method: (a) the 3D free-field system with uniform canyon cut in the foundation rock half-space; (b) the two-dimensional free-field system with corresponding 1D corner columns, reproduced from Lokke and Chopra [16].

inspection gangway that goes through all buttresses in openings of $2 \mathrm{~m} \times 1.5 \mathrm{~m}$.

The concrete material has modulus of elasticity $E_{c}=25 \mathrm{GPa}$, density $\rho_{c}=2400 \mathrm{~kg} / \mathrm{m}^{3}$, and Poisson's ratio $v_{c}=0.2$. The concrete buttresses are here assumed to be founded on rock in a rectangular canyon where the rock material parameters are $E_{f}=25 \mathrm{GPa}$, density $\rho_{f}=2400 \mathrm{~kg} / \mathrm{m}^{3}$, and Poisson's ratio $v_{f}=0.2$ [27]. For the water in the reservoir are the bulk modulus of $K_{r}=2.02 \mathrm{GPa}$ and density $\rho_{r}=1000 \mathrm{~kg} / \mathrm{m}^{3}$. Material damping of $1 \%$ and $2 \%$ are assumed for the dam and rock foundation, respectively [24]. It should be noted that a significant part of the damping in the dam-reservoir-foundation system is related to radiation damping, which is considered here by placing absorbing boundary conditions at truncated surfaces. Material damping in time-domain analyses can be defined by Rayleigh damping which required two parameters: mass proportional damping and stiffness proportional damping coefficients. In the analyses, the stiffness proportional damping coefficient of $5.13 \times 10^{-4} \mathrm{~s}$ and $1.03 \times 10^{-3} \mathrm{~s}$ were calculated for the dam and foundation, respectively. The mass proportional damping is omitted to prevent spurious damping forces that prohibit sliding and opening between sections $[28,29]$.

\section{Finite Element Model}

The three-dimensional finite element modelling is carried out using the finite element software ABAQUS [30]. The finite element model of the dam-reservoir-foundation system studied here is shown in Figure 4. The FE model of the dam is shown in Figure 4(a). Each monolith is discretised by 3036 solid elements (C3D8). The maximum element size considered in the analysis is less than one-eighth of the shortest wavelength of the slowest propagating body wave (shear wave) [31].

The contraction joints between the monoliths are highlighted in Figure 4(b). These are built with a water stop that has no shear resistance in the stream direction but can open and close during strong ground motion. A common method for modelling joints is a contact formulation at the surfaces between the monoliths $[17,32]$. Contraction joints in the tangential direction have no shear strength and are modelled as frictionless interaction interfaces. In the normal direction, the joints are modelled with a soft contact constraint that has an exponential relationship between pressure and overclosure:

$$
p= \begin{cases}0, & \text { for } d \leq-c_{0}, \\ \frac{p_{0}}{(e-1)}\left[\left(\frac{d}{c_{0}}+1\right)\left(e^{\left(\frac{d}{c_{0}}+1\right)}-1\right)\right], & \text { for } d>-c_{0},\end{cases}
$$

where $p$ is contact pressure, $d$ is overclosure, $p_{0}$ is contact pressure at zero opening, and $c_{0}$ is the initial contact distance. In an exponential (soft) contact pressure-overclosure relationship, the surfaces begin to transmit contact pressure once the clearance between them, measured in the contact (normal) direction, reduces to $c_{0}$. In the FE modelling of the joints $p_{0}=5 \mathrm{MPa}$ and $c_{0}=0.1 \mathrm{~mm}$ were assumed [33].

The dam-foundation interface in the normal direction is modelled using a zero tensile strength hard contact constraint to allow opening and closing of this joint. In the tangential directions, frictional sliding can be modelled by the penalty contact formulation based on the Coulomb friction model. Two contacting surfaces start sliding relative to one another when the shear stress exceeds the critical shear stress $\tau_{\text {crit }}=\mu p$, where $\mu$ is the coefficient of friction. Moreover, the penalty friction formulation includes a stiffness that allows some relative motion, i.e., elastic slip of the actual surfaces when they are in the sticking phase. The elastic slip is here specified by slip tolerance as a fraction of the element length. Here, a friction coefficient and a slip tolerance of 1 and 0.0001 are used $[33,34]$.

A full reservoir condition is considered with a depth of $38.5 \mathrm{~m}$. At the interfaces between reservoir water and dam-foundation, a tie constraint is used to connect acoustic fluid nodes to the solid. At the upstream end of the reservoir, a nonreflecting boundary was defined. A reservoir length with a minimum of twice of the reservoir depth is recommended to avoid reflection issues [33]. A reservoir length of 3.5 times the depth is considered here 


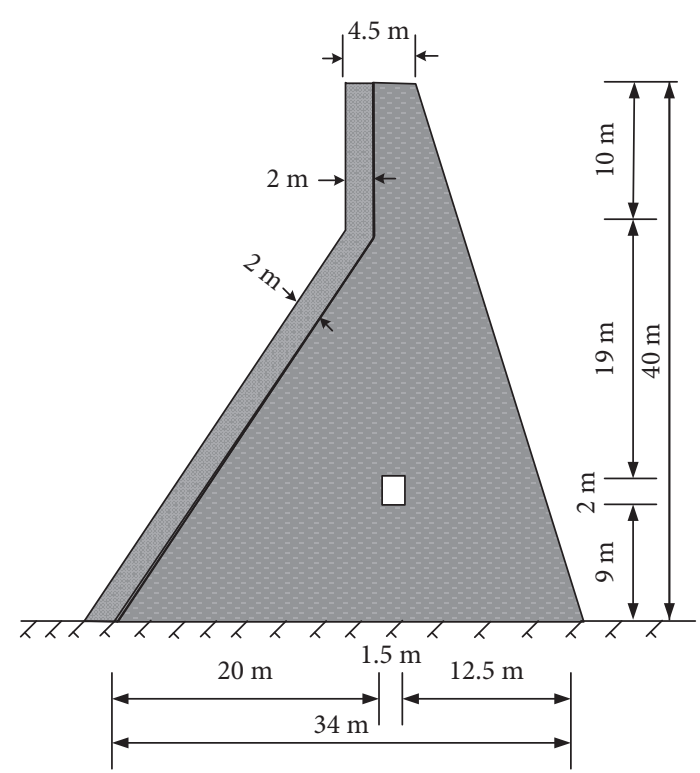

Figure 3: Geometry of the studied concrete monolith.

and the effect from the reservoir bottom sediments is ignored. For a FE model where water-foundation interaction and the associated radiation damping are included in the analysis, the additional vibration energy dissipation due to sediments is insignificant and therefore the sediments' effect can be ignored [24]. The reservoir water is discretised with 10816 acoustic elements (AC3D8) (Figure 4(c)).

The FE model of the rock foundation shown in Figure 4(d) consists of 14355 solid elements (C3D8) and 3107 infinite elements (CIN3D8) based on the work by Zienkiewicz et al. [35] for static response and by Lysmer and Kuhlemeyer [36] for dynamic response. The infinite elements perfectly absorb normal incident body waves to the boundary but partially absorb body waves with arbitrary incident angle and surface waves. However, an acceptable accuracy is obtained by placing the boundary at sufficient distance from the wave source [37]. From convergence analysis, a place of absorbing boundary conditions were obtained by extending the rock foundation to twice of the dam height, from the bottom of the dam and along the lateral sides in the cross-stream direction. The overall foundation size is $264 \mathrm{~m}$ in the stream and the cross-stream directions and $120 \mathrm{~m}$ in the vertical direction. For the massless foundation, it is recommended to determine the size of the foundation based on the ratio between the modulus of the foundation and that of the concrete $E_{f} / E_{c}$ to account for the flexibility of the foundation region [38]. For a competent foundation with $E_{f} / E_{c} \geq 1$, it is sufficient to extend the size of the foundation by one dam height in all directions. For a more flexible foundation with $E_{f} / E_{c}=1 / 2$ to $1 / 4$, the foundation model should extend by at least twice the dam height in all directions. Therefore, the foundation size considered here is larger than the recommended criteria.

Effective earthquake forces in the direct FE method are determined by two analyses, of a $1 \mathrm{D}$ column and a $2 \mathrm{D}$ system. Figure 5 shows steps for auxiliary analyses in computing effective earthquake forces by using the direct FE method. The effective earthquake forces at every node along the side is computed from equation (2) with $\dot{r}^{0}$ and $\mathbf{R}^{0}$ determined from analyses of a $1 \mathrm{D}$ column assumed at the along-canyon boundaries and of a $2 \mathrm{D}$ system at the cross-canyon boundaries at the upstream and downstream ends of the domain. The effective earthquake forces at the bottom boundary are calculated from equation (3). Auxiliary analyses were performed using Python programming to develop $1 \mathrm{D}$ and the 2D rock foundation systems and transferring forces. For the analytical method, a MATLAB script was used to obtain effective forces at the foundation boundaries' nodes, then assigned to each node in the finite element model.

\section{Earthquake Loads}

The design earthquake motions for dynamic analyses are usually given as outcrop motions. However, for a direct FE analysis, the seismic input must be applied at the base of the foundation. The corresponding input motion at depth can be calculated by a deconvolution analysis. This is usually done in the frequency domain by applying $1 \mathrm{D}$ shear wave (S-wave) propagation in horizontally layered media using a $1 \mathrm{D}$ wave propagation software, such as SHAKE [39] or DEEPSOIL [40], or by directly calculating the inverse of the transfer function for a $1 \mathrm{D}$ half-space [41]. A 1D wave propagation software usually calculates two different base motions at depth: a within motion and an outcrop motion. The within motion is the superposition of the incident and reflected waves, which gives the actual motion at a given depth in half-space. These types of base motions are suitable for input to a rigid base, where a time history of acceleration (or velocity or displacement) at the base is given. For example, a rigid base is suitable when simulating low velocity sediment over high velocity rock at the base [42]. The outcrop motion is the motion that would occur at a theoretical outcrop location (free surface) at the same depth to satisfy the zero shear stress condition at the free surface, where the upward and downward waves should be equal. Therefore, the outcrop motion is equal to twice the amplitude of the incident motion. This type of base motion is suitable for a compliant base where an absorbing boundary is used at the base [43].

To consider the deconvolution of pressure waves (P-waves), this paper develops a time-domain deconvolution method based on an iterative procedure using the model of a one-dimensional FE column subjected to vertical propagation of P- or S-waves. In this method, the frequency and amplitude of the incident wave are adjusted to obtain the motion of the target surface. In the first estimation, it is assumed that the motion of the base outcrop is identical to the target. Therefore, the incident wave is considered as half of the target motion. The effective earthquake forces are calculated from equation (3) and applied to the base of the 1D FE column: 


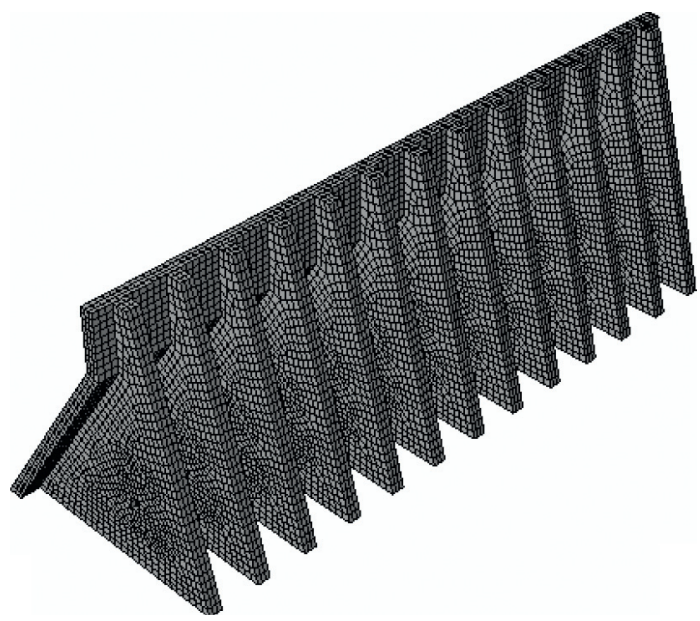

(a)

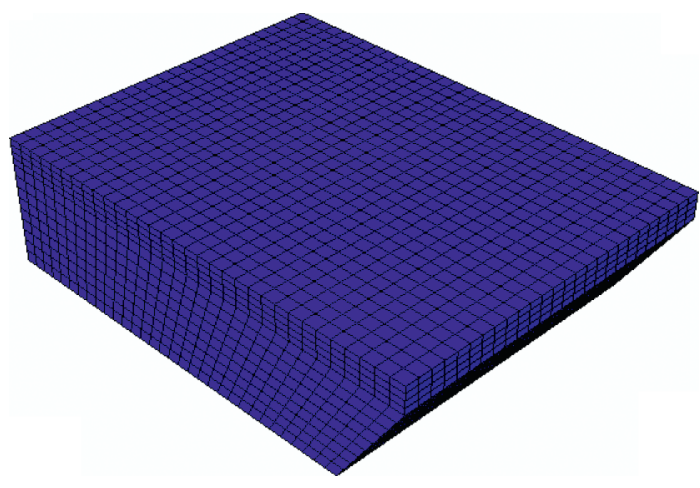

(c)

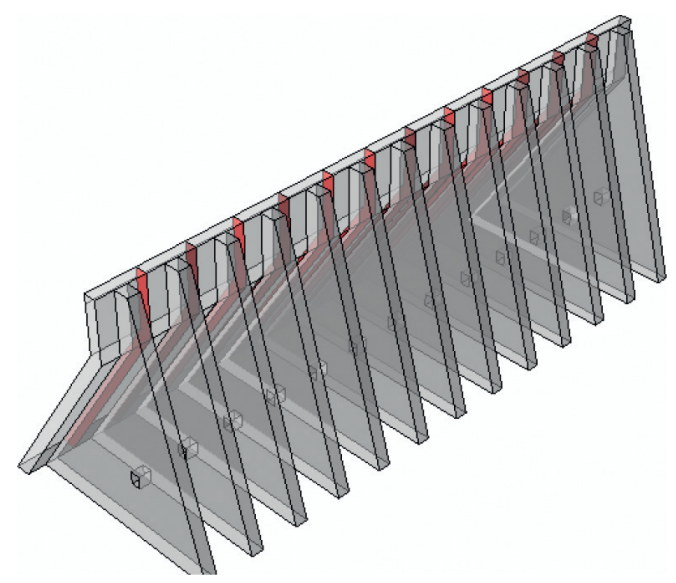

(b)

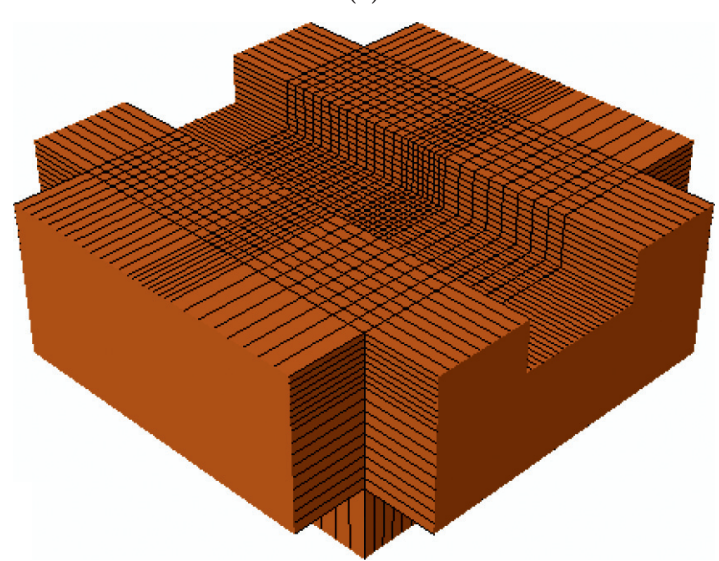

(d)

Figure 4: FE models of the studied concrete buttress dam (a), layout of contraction joints (b), reservoir (c), and rock foundation (d).

$$
\begin{aligned}
& F_{i}^{\text {Input }}(t)=2 \rho c_{s} \dot{u}_{i}^{\text {Input }}(t) \longrightarrow \mathrm{S}-\text { wave } \\
& F_{i}^{\text {Input }}(t)=2 \rho c_{p} \dot{u}_{i}^{\text {Input }}(t) \longrightarrow \mathrm{P} \text { - wave }
\end{aligned}
$$

where $\dot{u}_{i}^{\text {Input }}$ is the velocity time history of the incident wave. A $1 \mathrm{D}$ FE column subjected to the assumed incident wave is analyzed, and the surface and base acceleration time histories are recorded. A correction factor is then calculated by dividing the target response acceleration, $S_{a}^{\text {Target }}(\omega)$, by the response acceleration of the recorded motion at the free surface of the column $S_{a-i}^{\text {Response }}(\omega)$ :

$$
H(\omega)=\frac{S_{a}^{\text {Target }}(\omega)}{S_{a-i}^{\text {Response }}(\omega)} .
$$

The input motion is modified by multiplying the correction factor by the Fast Fourier Transform (FFT) component of the incident wave, $A_{i-1}^{\text {Input }}(\omega)$ :

$$
A_{i}^{\text {Input }}(\omega)=H(\omega) A_{i-1}^{\text {Input }}(\omega) .
$$

The new incident wave is transformed into the time domain by Inverse Fast Fourier Transform (IFFT). The 1D FE column is analyzed with the new input excitation and the free surface motion generated is compared to the target. The iteration procedure is continued until the response motion on the surface matches the target. The accuracy can be calculated using the Euclidian 2-norm:

$$
r=\frac{\|X-Y\|^{2}}{\|Y\|^{2}}=\frac{\sqrt{\sum_{j=1}^{j=n}\left|x_{j}-y_{j}\right|^{2}}}{\sqrt{\sum_{j=1}^{j=n}\left|y_{j}\right|^{2}}} \times 100 .
$$

In the final iteration step, the introduced acceleration time history at the base of the FE column is recorded as within motion consisting of incident and reflected waves. The outcrop motion is twice the modified input wave:

$\ddot{u}_{\text {deconvolved }}^{\text {within }}(t)=\ddot{u}_{i \text {-base }}^{\text {Response }}, \quad \ddot{u}_{\text {deconvolved }}^{\text {outcrop }}(t)=2 \ddot{u}_{i}^{\text {input }}$.

The procedure described is summarized in Figure 6. The other advantage of using deconvolution in the time domain is that the material properties considered in the FE column are the same as in the main FE model. For example, timedomain analysis uses Rayleigh damping, which is frequency dependent, while frequency domain analysis uses frequency independent damping. In the frequency domain, the nonlinearity of the ground is taken into account by the equivalent linear approach. Furthermore, the available 


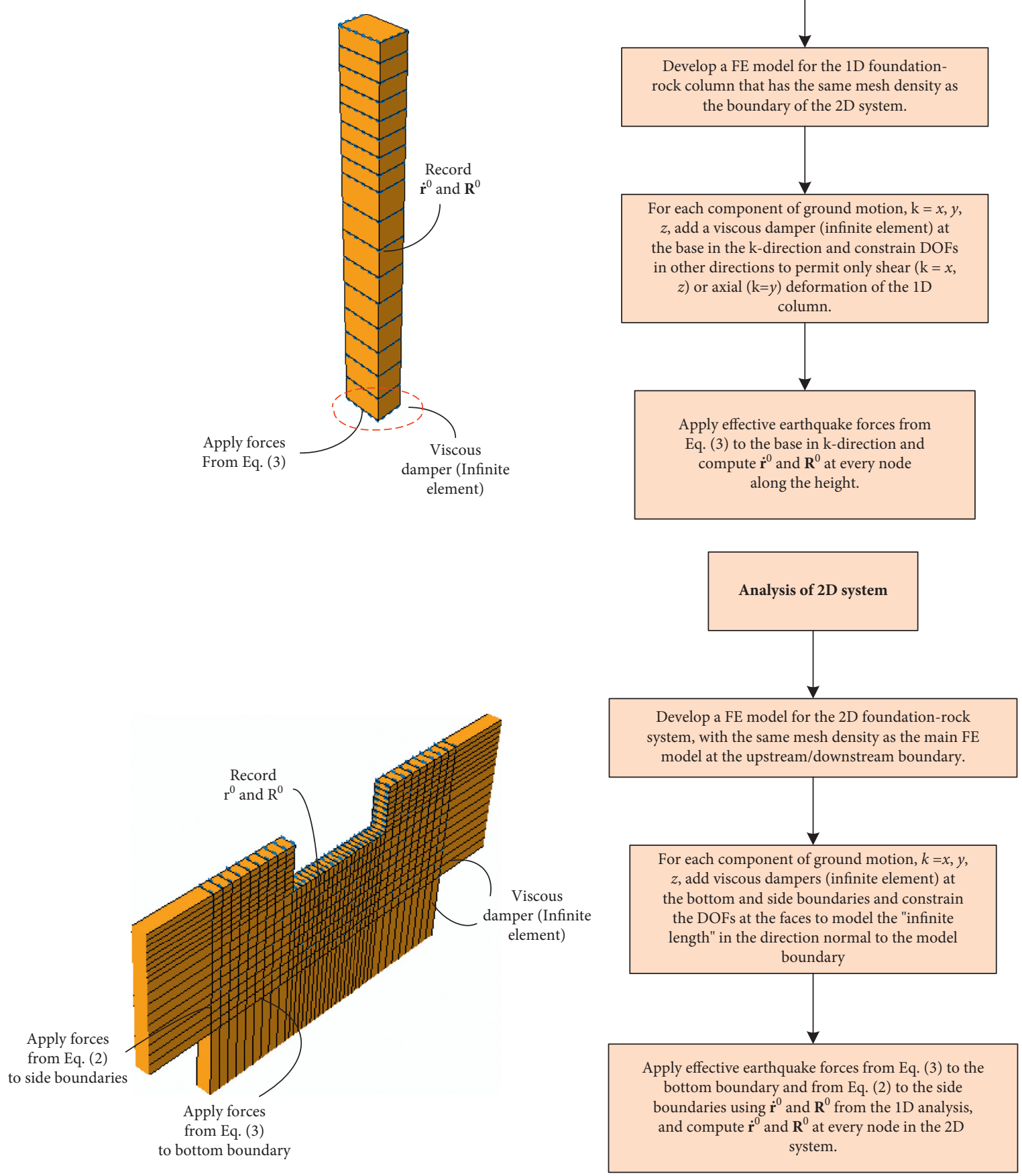

FIGURE 5: Steps for auxiliary analyses for computing effective earthquake forces by using the direct FE method. 
deconvolution software is based on the vertical propagation of shear waves $[39,40]$. Here, deconvolution is performed for both P- and S-waves.

The described procedure is used in this work to deconvolve the seismic input motions. In areas of low seismicity, the dams should be designed for an earthquake with a return period of at least 10000 years [44]. Due to the absence of such records, the excitation with high-frequency content is chosen based on artificial accelerograms corresponding to Swedish hard rock response spectra [45]. The low-frequency ground motion is based on acceleration time histories recorded during the 1952 Kern County earthquake (station: Taft Lincoln School) [46]. The Taft earthquake was scaled to have the same peak ground acceleration (PGA) as the Swedish design earthquake, which has PGA of $0.146 \mathrm{~g}$, $0.122 \mathrm{~g}$, and $0.090 \mathrm{~g}$ in the stream, cross-stream, and vertical directions, respectively. To perform the deconvolution, a control point (a point on the free ground surface) is selected at the abutments top surface of the rock foundation. The iteration procedure was performed to achieve an error of less than $2 \%$ between the free surface (target) motion and the convolved motion recorded at the surface of the column (see Figure 7). It can also be seen from the figure that the highfrequency excitation was dominated by frequencies between 10 and $20 \mathrm{~Hz}$ and that the low-frequency component was dominated by frequencies in the range of $2-7 \mathrm{~Hz}$.

\section{Numerical Results}

In the following, the results of the analyses of the concrete buttress dam are presented. First, an eigenvalue analysis is performed to investigate the mechanical properties of the FE models. Then, seismic analyses are performed in two steps. Gravity and hydrostatic pressure loads are applied in the initial static step, and in the subsequent step, nonlinear dynamic analyses are performed in an implicit step using the HHT-alpha time integration scheme and an automatic timestepping control that changes the time increment depending on the convergence rate of the solution.

7.1. Eigenvalue Analysis. To investigate the natural frequencies of the concrete dam, a massless foundation approach is motivated and used here since all nonstructural modes emanating from the rock mass are suppressed. In the linear eigenvalue analyses, the nonlinear behaviour cannot be taken into account, so the contraction joints are modelled as hinges. The free vibration modes of the monoliths in the buttress dam correspond to relatively high natural frequencies, all calculated above $6.00 \mathrm{~Hz}$. A significant part of the mass of the buttress dam system is active above $7.00 \mathrm{~Hz}$. The results here are divided into two different types of bending modes: lateral bending and bending in the stream direction. Their natural frequencies are close together, with several modes just above $6.00 \mathrm{~Hz}$. The buttress monoliths exhibit several lateral bending modes, with the first, second, and third lateral bending modes of the central monolith corresponding to frequencies of $6.00 \mathrm{~Hz}, 10.00 \mathrm{~Hz}$, and $18.00 \mathrm{~Hz}$, respectively, as shown in Figure 8. This shows that the buttress dam can be sensitive to cross-stream excitations, especially at frequencies above $7.00 \mathrm{~Hz}$.

7.2. Influence of Irregular Topography on the Free Surface Motion of the Foundation. Figure 9 shows the distribution of peak ground acceleration (PGA) recorded at the free surface of the canyon due to the Swedish design earthquake. The motions at the free surface are shown in the stream, crossstream, and vertical directions for free-field modelling of the rock foundation using the direct FE method, the analytical method, and the massless method. It can be seen from the figures that modelling the foundation considering the rock mass with the direct FE and the analytical method leads to an uneven distribution of the surface movements in all directions. The massless approach results in uniform movement along the free surface of the canyon. Since the mass of the foundation is neglected, this leads to an infinite wave propagation velocity. Therefore, the seismic waves at the upper surface of the rock are identical to the applied excitation at the rock boundaries.

The Swedish design earthquake results in significant variations of the PGA along the free surface of the canyon. In the stream direction, the maximum acceleration is triggered in the middle of the canyon, where the dam is located, with a value of $1.60 \mathrm{~m} / \mathrm{s}^{2}$. The accelerations at the right abutment at coordinate $+52.00 \mathrm{~m}$ are higher than at the left, where the acceleration difference between the upper points of the abutments is $0.14 \mathrm{~m} / \mathrm{s}^{2}$. In the cross-stream and vertical directions, two acceleration peaks occur for the points at the base of the canyon. Furthermore, the distribution of the PGA along the canyon is not symmetrical. In the cross-stream direction, the acceleration in the canyon increases from the centre with a value of $1.20 \mathrm{~m} / \mathrm{s}^{2}$ to $1.30 \mathrm{~m} / \mathrm{s}^{2}$ at the coordinate of $+17.00 \mathrm{~m}$. The top point at the right abutment has the highest acceleration of $1.60 \mathrm{~m} / \mathrm{s}^{2}$. In the vertical direction, maximum accelerations of $1.25 \mathrm{~m} / \mathrm{s}^{2}$ and $2.00 \mathrm{~m} / \mathrm{s}^{2}$ occur at the coordinates of $-27.00 \mathrm{~m}$ and $+52.00 \mathrm{~m}$, respectively. It can also be seen that the discrepancies between the motions of the free surface calculated with the direct FE and the analytical methods are small, but the analytical approach mainly overestimates the motions. The small differences are due to the fact that in the direct FE method, the free-field system is identical to the actual system in the region outside the nonreflected boundaries. In the analytical method, the free-field system was simplified to the one-dimensional column.

Compared to the Swedish design earthquake, the Taft earthquake shows a more uniform motion without peaks in the centre of the canyon and towards the abutments, as given in Figure 10. In the stream direction, the distribution of the PGA is almost symmetrical and there are small differences between the motions at the abutments. The maximum PGA of $1.20 \mathrm{~m} / \mathrm{s}^{2}$ and $1.40 \mathrm{~m} / \mathrm{s}^{2}$ occurs in the canyon and at the top point of the abutment, respectively. The motions, in the cross-stream direction are more asymmetrical compared to the stream direction, with higher acceleration at the right abutment than at the left. It can also be seen that the 


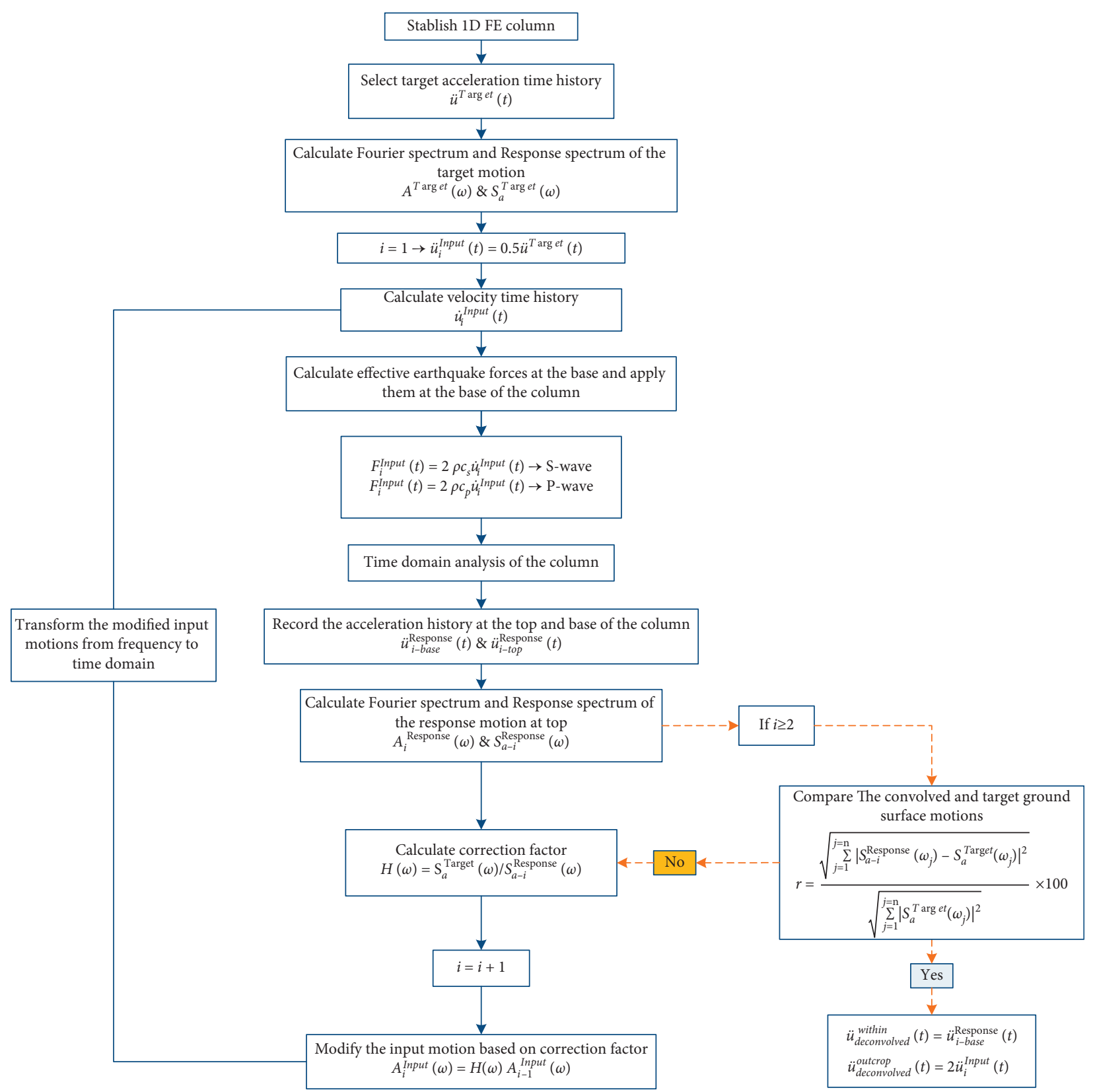

Figure 6: Deconvolution of the seismic surface ground motions using the time-domain iteration method.

discrepancy between the analytical method and the direct FE method is greater than the other cases shown in Figures 9 and 10. The maximum PGA caused by the direct FE method is $1.04 \mathrm{~m} / \mathrm{s}^{2}$ and for the analytical method it is $0.91 \mathrm{~m} / \mathrm{s}^{2}$. The difference in acceleration between the upper points of the abutments is $0.15 \mathrm{~m} / \mathrm{s}^{2}$, with the right side having a PGA of $1.40 \mathrm{~m} / \mathrm{s}^{2}$. In the vertical direction, the distribution is more uniform and close to the massless induced motion.

The comparison between the free surface motions produced by high-frequency excitation and low-frequency excitation shows that for the high-frequency case, it is important to choose a suitable and correct approach to accurately capture the topographic amplifications on the surface of the foundation. For high-frequency excitation, there is a significant difference between the massless approach and the two approaches with free-field forces. For low-frequency excitation, the peak acceleration is more or less constant along the canyon and slightly lower than at the top. With the high-frequency excitation, the peak acceleration is not constant along the upper part of the rock foundation. There is also a significant variation in acceleration along the canyon. The peak typically occurs in the middle or near the middle of the canyon.

\subsection{Influence of the Free-Field Modelling of the Foundation on} the Computed Response of the Dam. Figure 11 shows the distribution of the PGA triggered by the Swedish design earthquake along the crest of the dam. The results are shown 

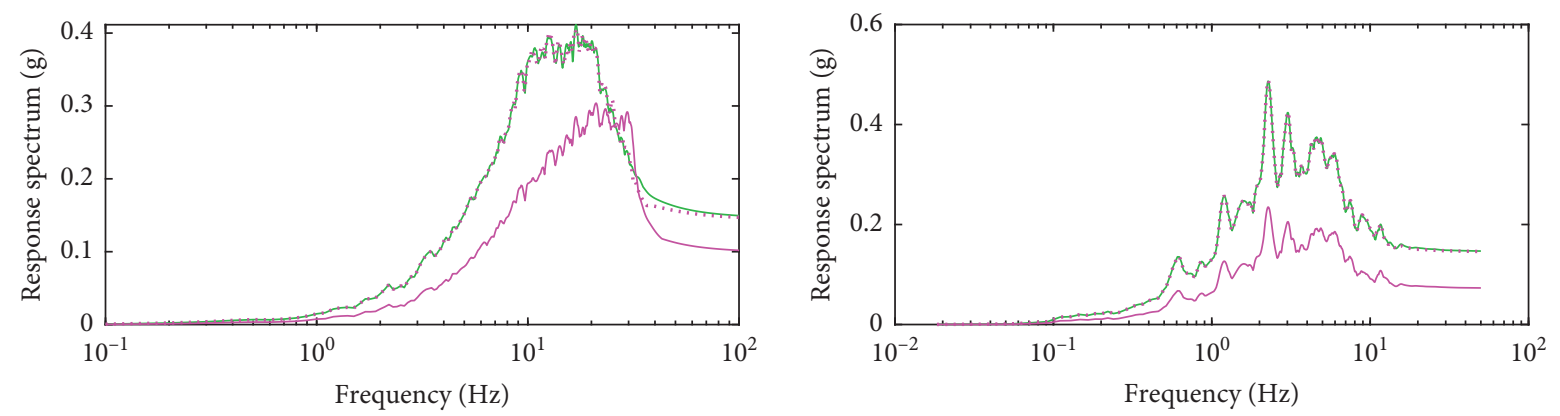

- Free surface

- Modified input motion

..... Recorded at surface

(a)
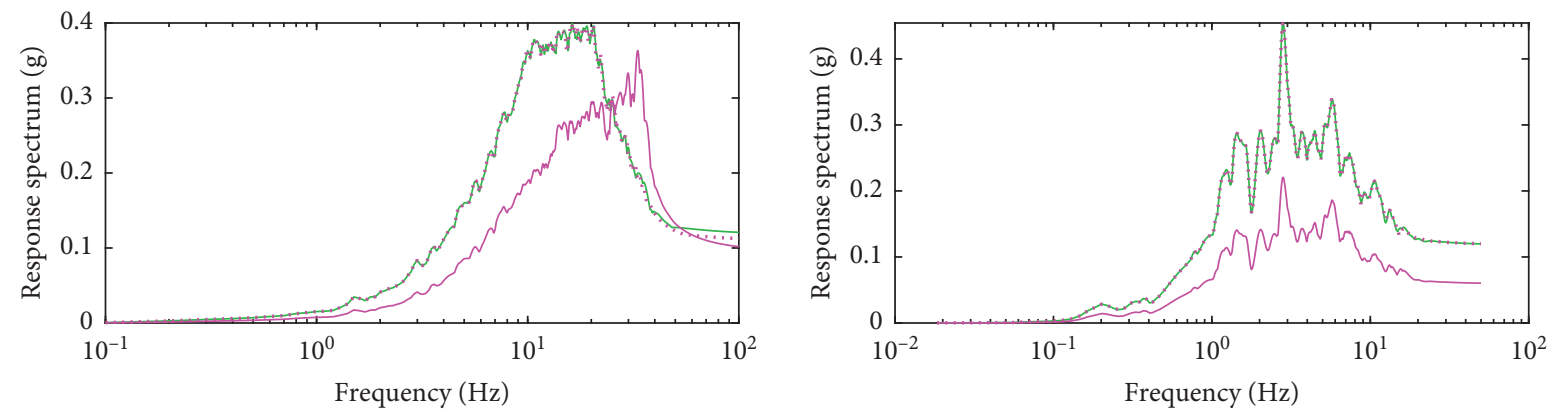

(b)
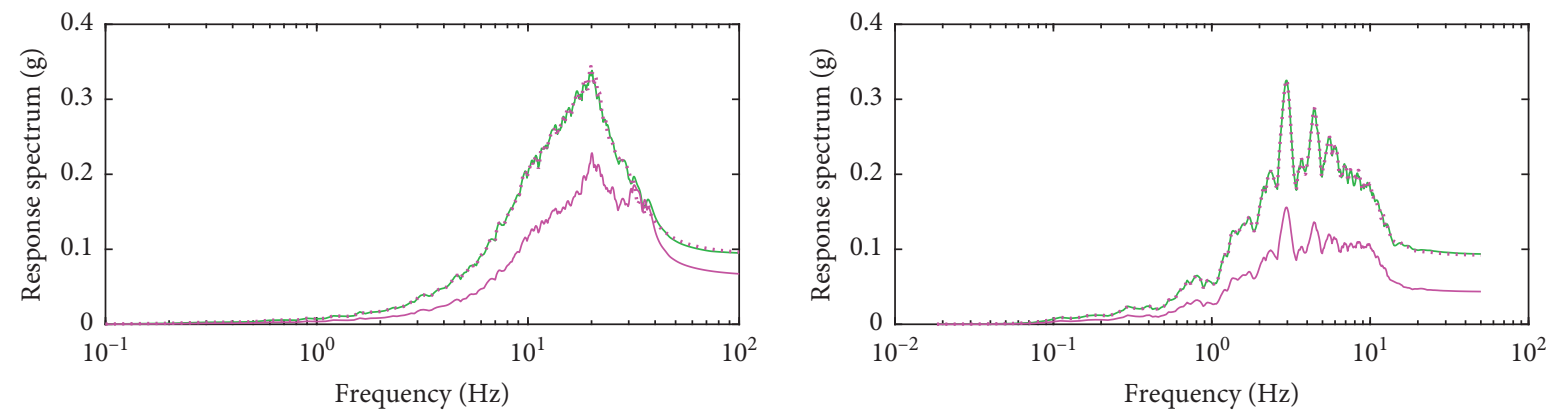

(c)

FiguRE 7: Acceleration response spectrum of Swedish design earthquake (left) and Taft earthquake (right) at free surface (control point), at base (deconvolved), and recorded at column surface (convolution), in the (a) stream, (b) cross-stream, and (c) vertical directions.

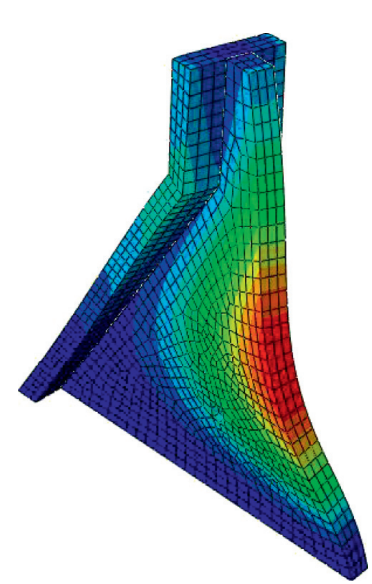

$f=6.18 \mathrm{~Hz}($ mode 1$)$

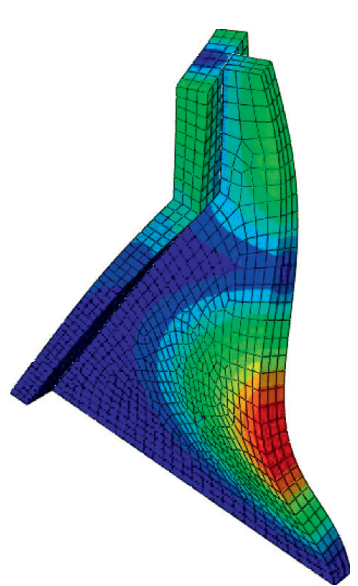

$f=10.04 \mathrm{~Hz}(\operatorname{mode} 18)$

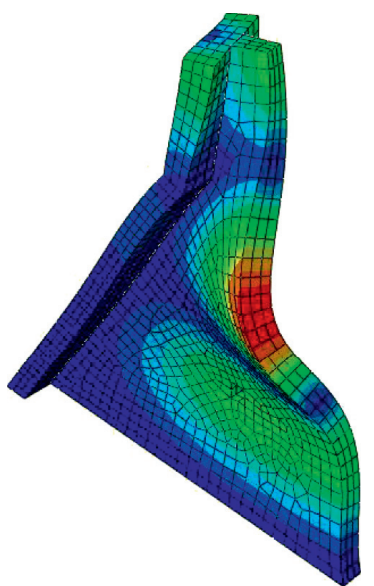

$f=18.28 \mathrm{~Hz}$ (mode 54)

Figure 8: Lateral bending mode shapes of the middle monolith. (a) $f=6.18 \mathrm{~Hz}$ (mode 1), (b) $f=10.04 \mathrm{~Hz}$ (mode 18), and (c) $f=18.28 \mathrm{~Hz}$ (mode 54). 

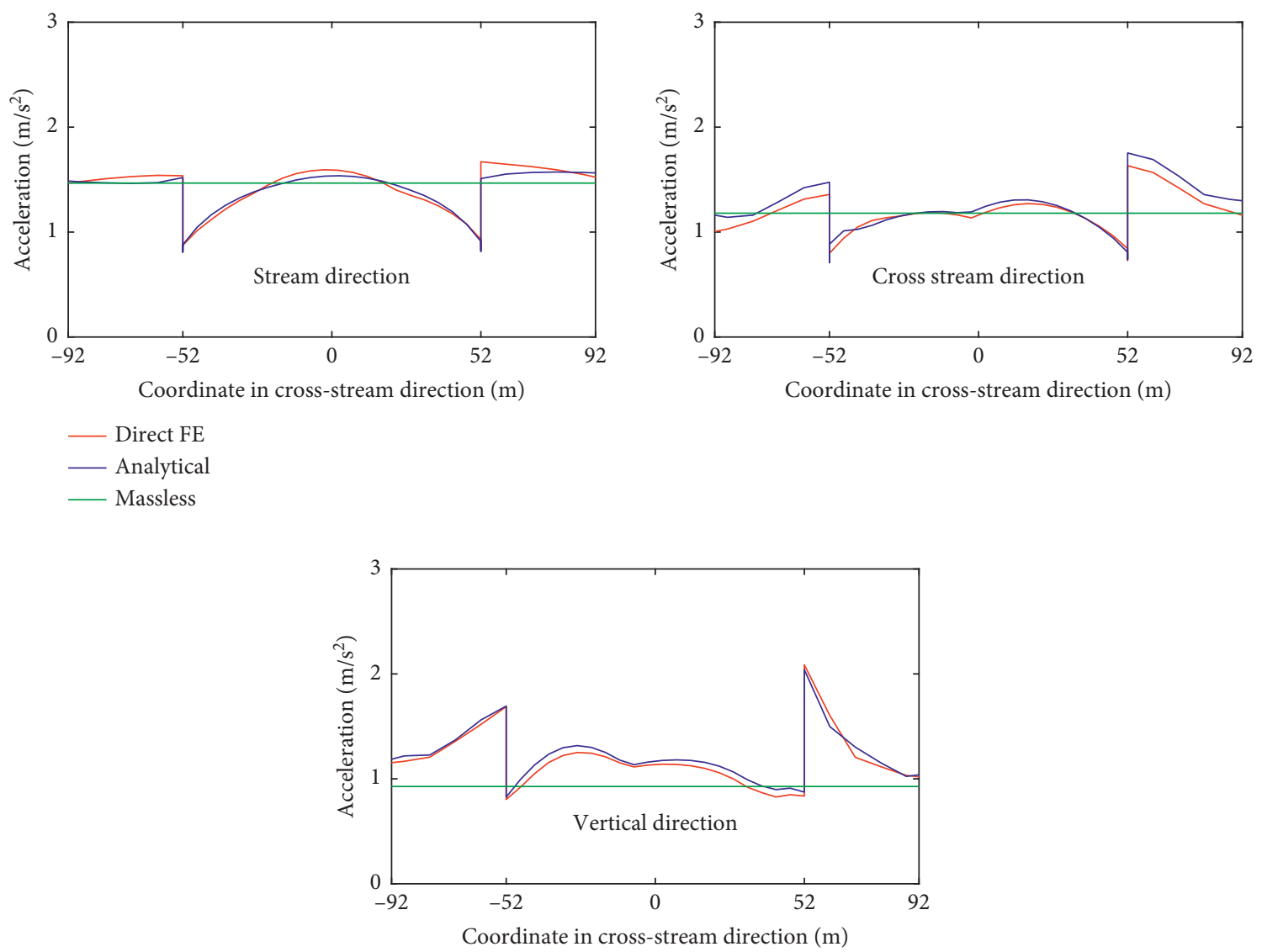

FIGURE 9: Distribution of PGA recorded at points along the canyon free surface induced by the Swedish design earthquake in the (a) stream, (b) cross-stream, and (c) vertical directions for free-field modelling of the rock foundation using the direct FE method, analytical method, and massless method.

for the stream and cross-stream directions. In the stream direction, the models taking into account the foundation mass lead to significant deviations of the PGA along the dam crest. There is clearly an influence of the 13 buttress monoliths, with the peak occurring at the joints. The points with the lowest acceleration correspond to where the buttresses are attached to the front plates. Due to the additional mass, the accelerations are lower at the centre of the front plate of each monolith. It can also be seen that the distribution of the PGA along the crest is not symmetrical. The same behaviour can be seen in Figure 9, where the acceleration at the right abutment was higher than at the left. This also results in the monoliths near the rock having higher accelerations.

The massless method resulted in sliding failure due to loss of contact between the rock foundation and the dam after almost 8 seconds in the simulation, as shown in Figure 12(a). Therefore, using a massless method would lead to the conclusion that the dam is not safe and requires strengthening to withstand this seismic excitation. At the same time, the analyses with mass foundation, which model the foundation more realistically, obtain a significant radiation damping which reduces the risk for this sliding failure. Significant overestimation of the vibration induced in the dam due to the massless approach has also been investigated in $[17,18,26]$. To overcome this problem, many researchers have used unrealistically high damping ratios around $15 \%$ to fit the results to the measurements [47]. Here, also by increasing the damping to $5 \%$, the risk for sliding failure could be reduced, as shown in Figure 12(b).

In the stream direction, free-field modelling with the direct FE and the analytical methods lead to similar responses at the crest, while there are discrepancies between the two methods in the cross-stream direction. The differences are significant at coordinates between $-52 \mathrm{~m}$ and $-36 \mathrm{~m}$, corresponding to monoliths one and two, where the analytical method overestimates the acceleration. The reason for these discrepancies is that there is an effect of opening joints in the cross-stream direction that significantly affects the acceleration at the crest. Figure 13 shows the distribution of the maximum joint opening at the crest and as can be seen from the figure, the maximum joint opening occurs at the first joint with a coordinate of $-44 \mathrm{~m}$, with the largest difference between the direct FE and the analytical methods. The joint opening for the analytical method is $1.55 \mathrm{~mm}$, which is $0.3 \mathrm{~mm}$ higher than for the direct method. As mentioned earlier, the discrepancy between the accelerations calculated by the direct FE and analytical methods is greater at monolith one and two, where joint one is located.

Figure 14 illustrates the distribution of PGA at the crest caused by the Taft earthquake in the stream and cross-stream 

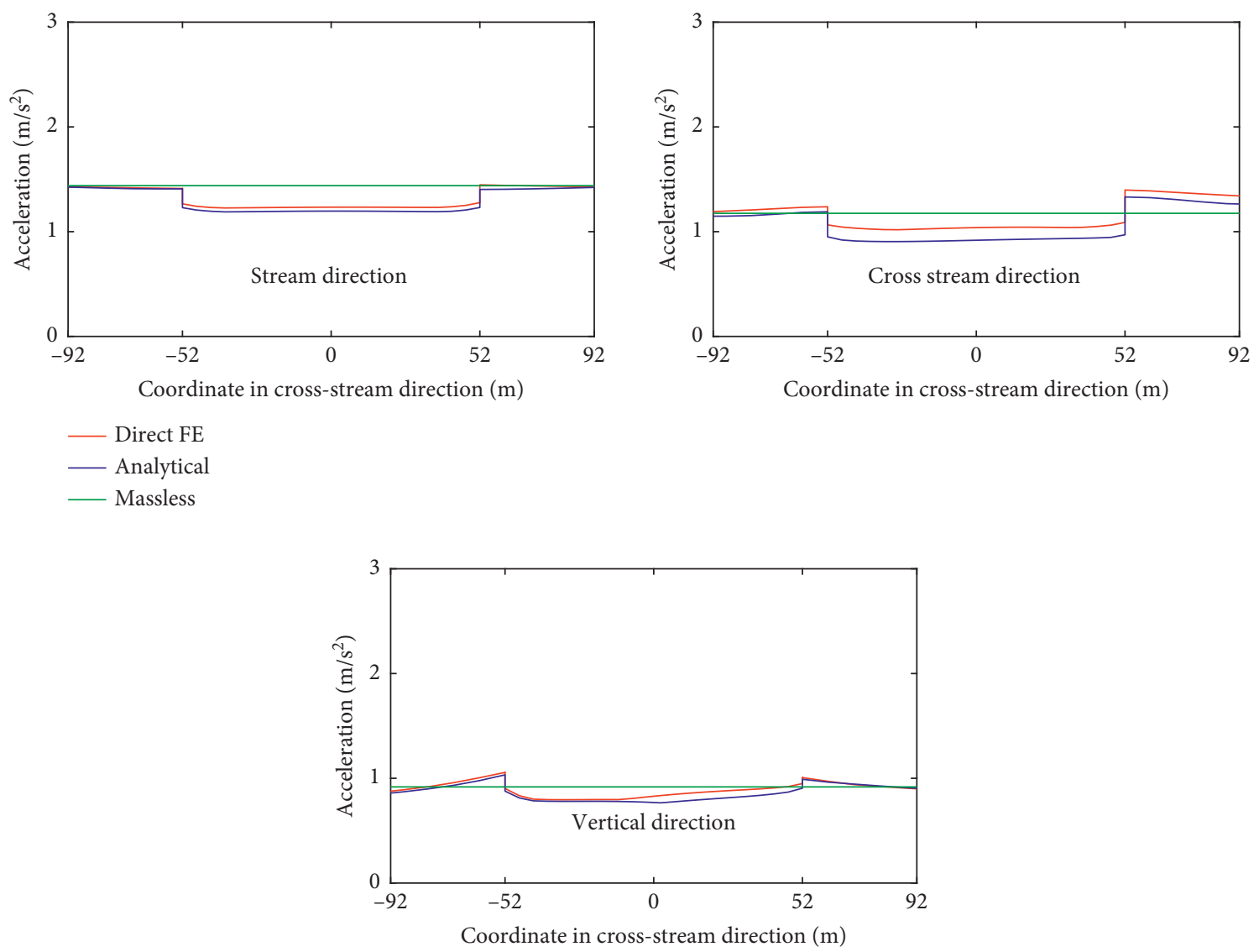

FIGURE 10: Distribution of PGA recorded at points along the canyon free surface induced by the Taft earthquake in the (a) stream, (b) crossstream, and (c) vertical directions for free-field modelling of the rock foundation with the direct FE method, analytical method, and massless method.

directions. In the stream direction, with the exception of the two lateral monoliths, the massless method overestimates the accelerations compared to the methods that consider the foundation mass. The distribution of PGA at the crest is uniform except for three peaks induced by the direct FE method, and the variation of acceleration at each monolith is much smaller than the variation induced by the Swedish design earthquake (see Figure 11). This behaviour is related to the topographic amplification of the motion at the free rock surface, which is smooth in the Taft earthquake compared to the Swedish design earthquake (see Figure 10).

In the cross-stream direction, the direct $\mathrm{FE}$ method yields higher accelerations than the other methods. The massless method and the analytical method yield similar accelerations in this case. This behaviour is in contrast to the behaviour observed at the dam heel, where the massless method overestimates the accelerations compared to the other methods. This is because at the dam crest, where most of the joint openings occur, the accelerations are more influenced by the nonlinear behaviour of the joints. Figure 15 shows that the joint opening for the direct FE method is significantly higher than for the other methods. The maximum joint opening for the direct FE method is $2.0 \mathrm{~mm}$, while it is $0.5 \mathrm{~mm}$ for the analytical method, and $0.7 \mathrm{~mm}$ for the massless method.
The opening and closing of the joint appears to initiate an impact load that causes high-frequency acceleration at the crest for a short time. For the Swedish design earthquake, both the direct FE method and the analytical method were able to detect these high frequencies. For the joints near the abutments, which have a larger joint opening, there is a significant amplification of acceleration at frequencies above $20 \mathrm{~Hz}$, while this is not the case for the joints in the central part of the dam, which have smaller joint openings. In the direct FE method for the Taft earthquake, which has a larger joint opening compared to the analytical method, all joints produce high-frequency accelerations above $10 \mathrm{~Hz}$. For the joints near the abutments, which have a larger joint opening, the amplification of the acceleration is too large, so that frequencies below $10 \mathrm{~Hz}$ are also affected. Figure 16 shows the time history of the opening of the $7^{\text {th }}$ joint (at coordinate 4 in Figure 15). It can be seen that the time history for the direct FE method contains four peaks, with the first having the highest opening of $0.53 \mathrm{~mm}$.

The acceleration time history for a middle point at the dam crest from the direct FE method also contains four peaks in the same time interval as for the joint opening, as shown in Figure 17. The peaks mentioned contain highfrequency accelerations above $10 \mathrm{~Hz}$, which can be seen in the response spectrum of the acceleration time history. 

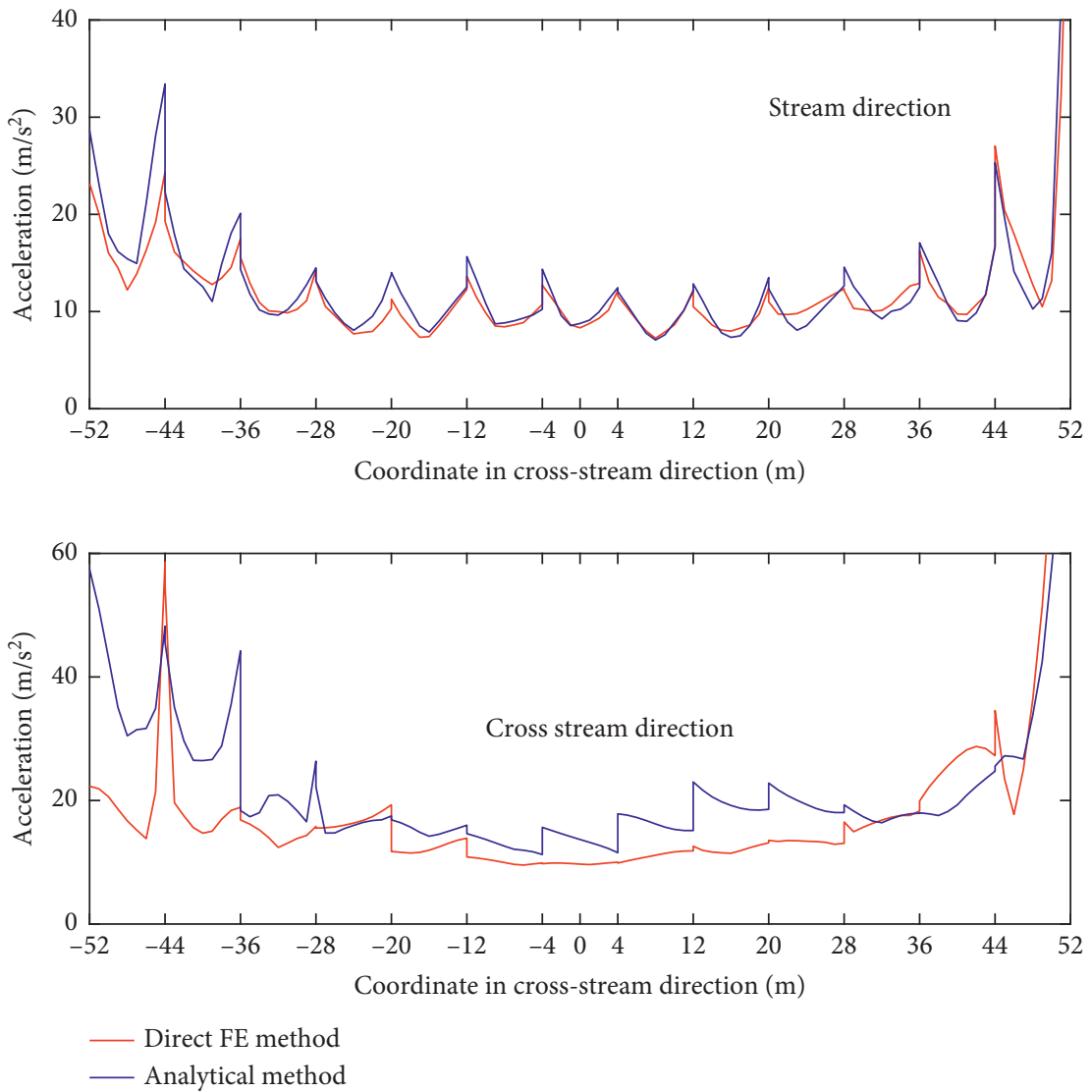

Figure 11: Distribution of PGA at upstream side of the buttress dam along the crest induced by the Swedish design earthquake in the (a) stream and (b) cross-stream directions for foundation modelling using direct FE method and analytical method.

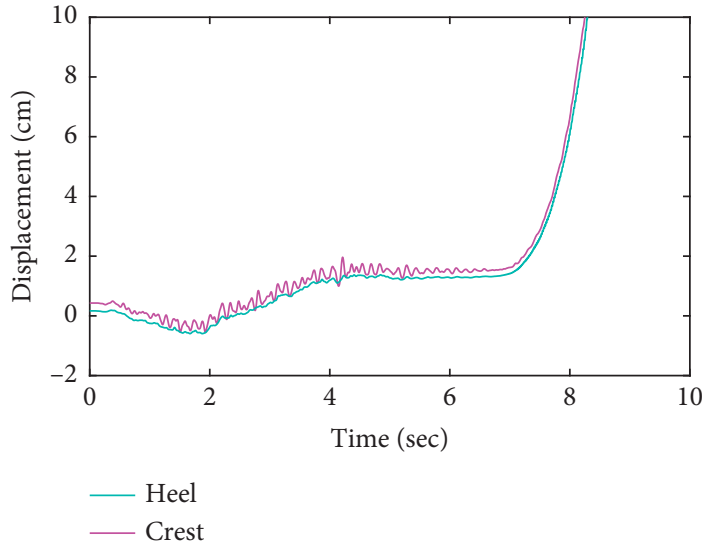

(a)

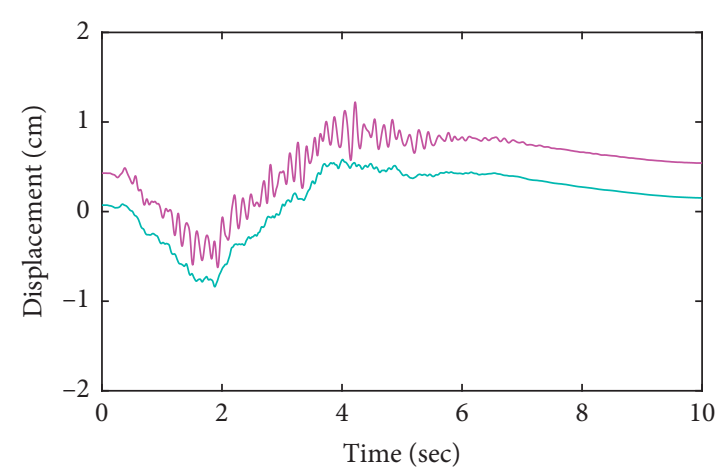

(b)

Figure 12: Displacement time history induced by the Swedish design earthquake for the midpoint at the crest and heel of the dam in the stream direction with a Rayleigh damping of $1 \%$ (a) and $5 \%$ (b).

Therefore, the analyses show that it is important to use an accurate modelling approach for the rock foundation, especially in cases where nonlinearity is considered. It has been shown that the joint opening can be over- or underestimated when using the analytical approach compared to the direct FE approach. It should be noted that free-field modelling using the analytical method is as accurate as the direct FE method for seismic analysis of concrete gravity dams, where a linear two-dimensional model of dam-reservoir-foundation is implemented. This is because for two-dimensional models, the free-field system is a one-dimensional column for both the direct FE method and the analytical method. 


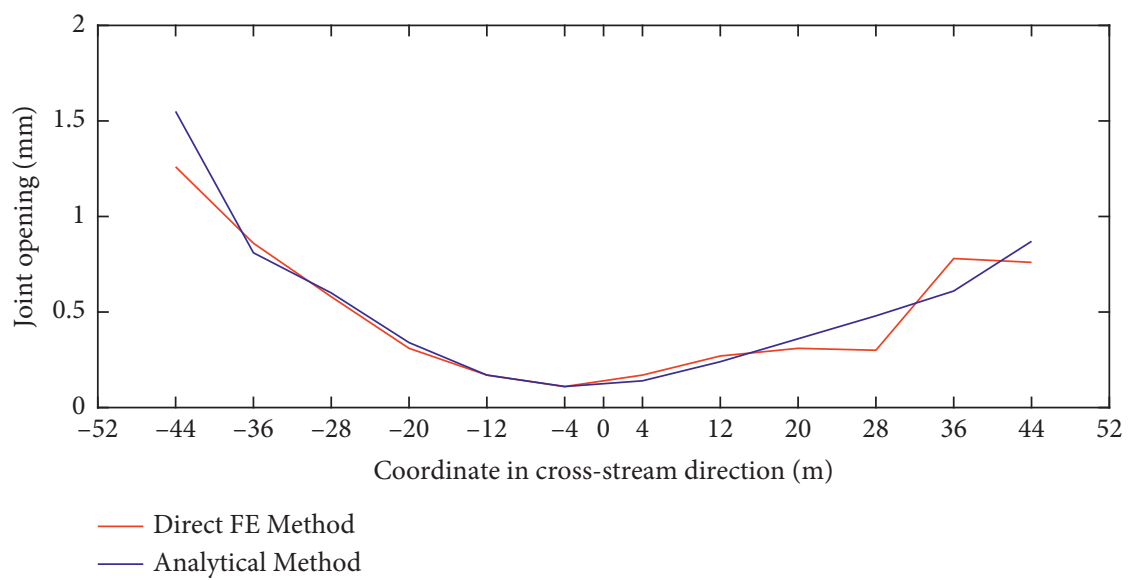

FIGURE 13: Maximum envelope of joint opening at the crest due to the Swedish design earthquake for foundation modelling using direct FE method and analytical method.

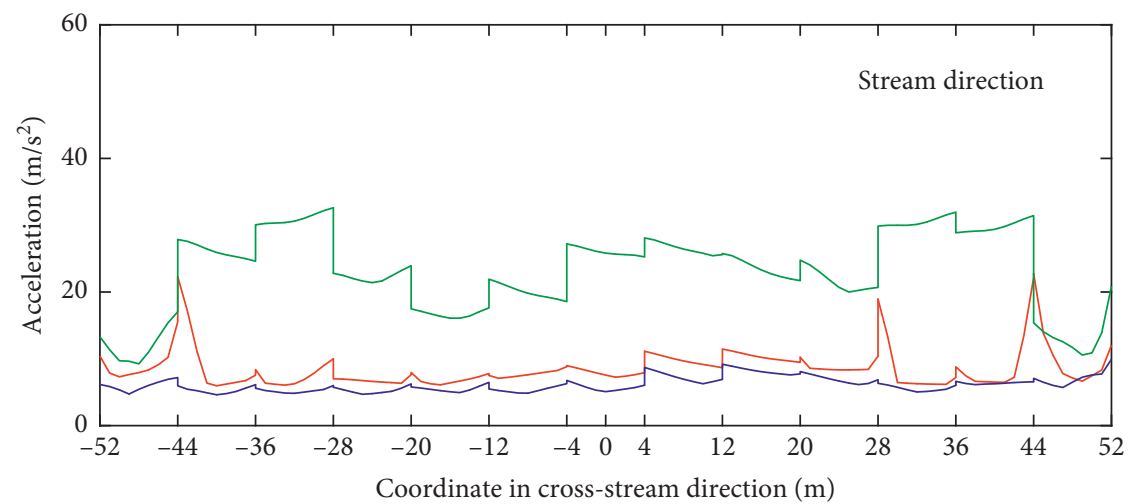

- Direct FE Method

- Analytical Method

— Massless Method

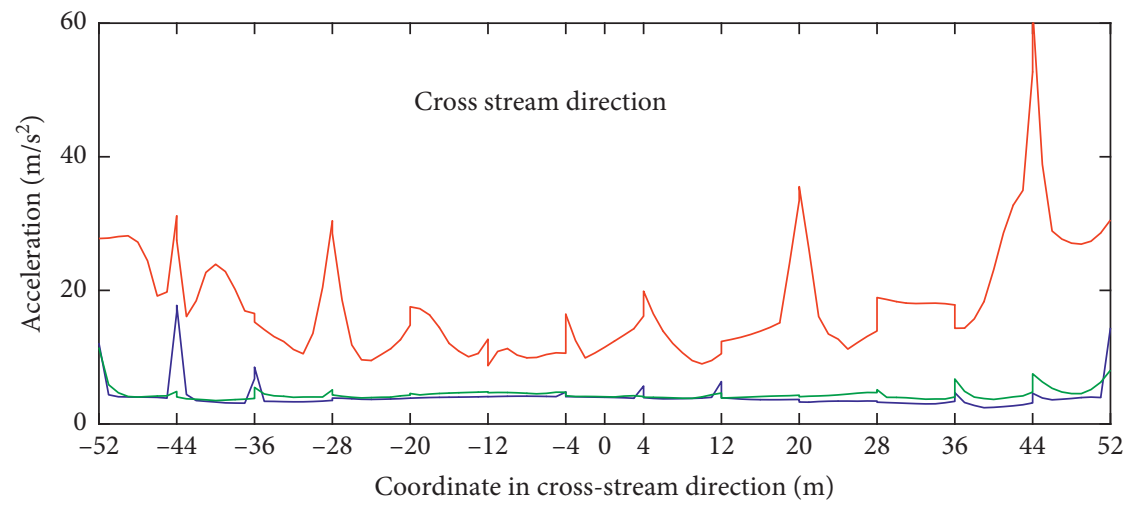

FIGURE 14: Distribution of PGA at upstream side of the buttress dam along crest induced by the Taft earthquake in the (a) stream and the (b) cross-stream direction for foundation modelling using direct FE method, the analytical method, and the massless method.

The analytical method has been used for linear two-dimensional modelling of concrete gravity dams, e.g., by Enzell et al. [48] and Chen et al. [49].

7.4. Influence of the Structural Slenderness on the Dam Response. Here, the influence of the structural slenderness of the buttress on the response of the dam is discussed by comparing the response spectrum of the acceleration time histories generated during the passage of the seismic wave at the dam heel, at the cross-section change, and at the dam crest also with the free surface motion of the foundation. The predominant frequency interval of the free surface of the foundation for the Swedish design earthquake is $10.0-20.0 \mathrm{~Hz}$. In the stream direction, the frequency interval 


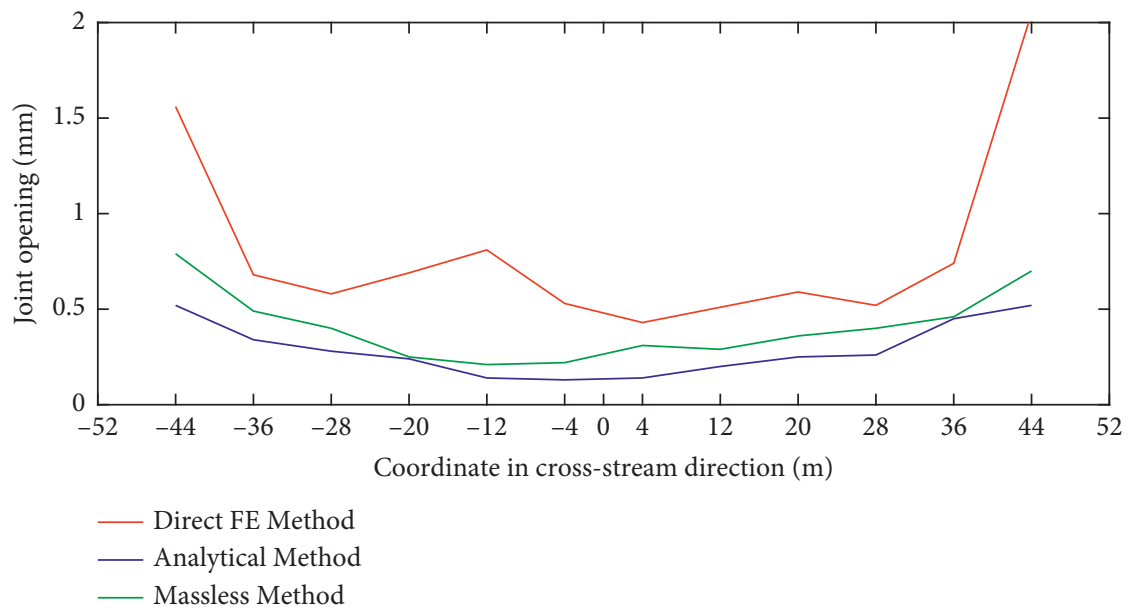

FIgURE 15: Maximum envelope of joint opening at crest due to the Taft earthquake for foundation modelling using the direct FE method, the analytical method, and the massless method.

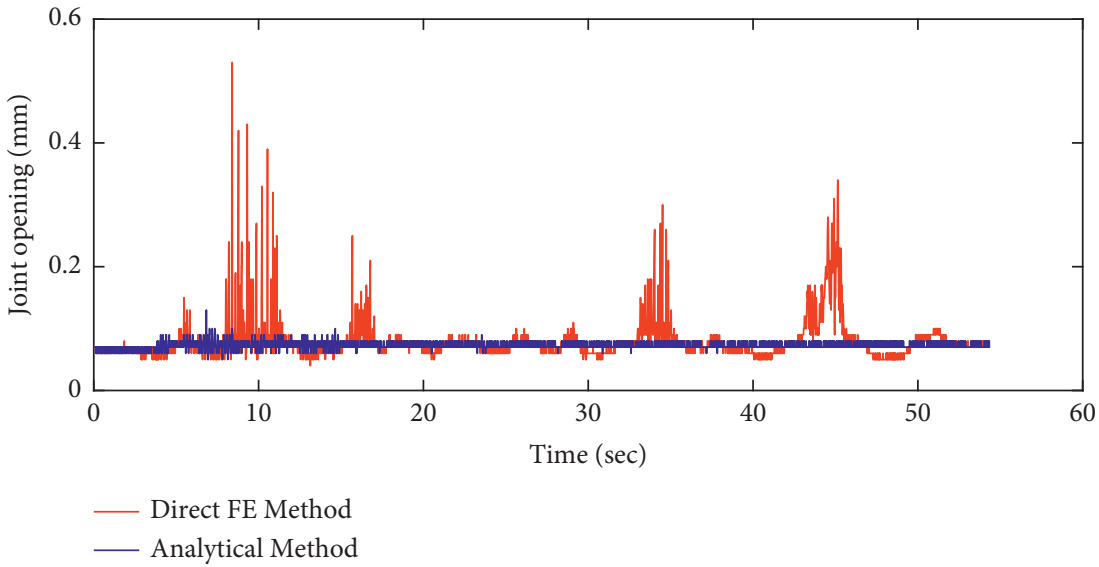

FIGURE 16: Time history of joint opening at joint $7^{\text {th }}$ induced by the Taft earthquake for foundation modelling using the direct FE method, analytical method, and the massless method.

of $12.5-17.0 \mathrm{~Hz}$ is left at the heel, as shown in Figure 18. Two frequency intervals of $6.6-8.0 \mathrm{~Hz}$ and $12.3-13.3 \mathrm{~Hz}$ are excited at the cross-section change. A frequency interval of $6.6-8.0 \mathrm{~Hz}$ is also excited at the crest, but the dominant frequency interval is $12.7-15.7 \mathrm{~Hz}$. The excited frequencies are natural frequencies of the buttress moving upstream and downstream, i.e., the stream bending modes. In the crossstream direction at the heel, a frequency interval of $11.0-21.0 \mathrm{~Hz}$ is excited. At the cross-section change and at the crest, two frequencies of $10.4 \mathrm{~Hz}$ and $30.0 \mathrm{~Hz}$ are excited, corresponding to the second and fourth lateral bending modes.

For the Taft earthquake, the response spectrum of the acceleration time history is presented for the model with free-field modelling of the foundation using the analytical method because, as shown in Figure 17, the high-frequency accelerations in the cross-stream direction are due to the nonlinearity of the joints. The predominant frequency of the free surface of the foundation due to the Taft earthquake is $2.8 \mathrm{~Hz}$. In the direction of the stream, the frequency of $6.2 \mathrm{~Hz}$ is excited at the heel and at the cross-section change, as shown in Figure 19. At the crest, frequencies of $6.2 \mathrm{~Hz}$ and $12.5 \mathrm{~Hz}$ are excited, which are lower than the dominant frequency interval excited by the Swedish earthquake, where the dominant frequencies were above $12.7 \mathrm{~Hz}$. In the crossstream direction, a frequency of $2.8 \mathrm{~Hz}$ is excited at the heel and frequencies of $2.8 \mathrm{~Hz}, 4.8 \mathrm{~Hz}$, and $10.0 \mathrm{~Hz}$ are excited at the cross-section change. At the crest, frequency intervals of $5.1-5.8 \mathrm{~Hz}$ and $9.8-13.0 \mathrm{~Hz}$ are excited. The frequency interval of $5.1-5.8 \mathrm{~Hz}$ was not captured in the eigenvalue analysis, but the frequency of $9.8 \mathrm{~Hz}$ is close to the second lateral bending mode, as shown in Figure 8.

The amplification of acceleration between the crest of the dam and the heel in the middle of the dam in the stream and cross-stream directions is between 4 and 5 times for both earthquakes. However, this amplification is in the frequency range of $10-30 \mathrm{~Hz}$ for the high-frequency excitation, while it is between $5-13 \mathrm{~Hz}$ for the low frequencies. This shows that the buttress has higher natural frequencies due to its slenderness, which are influenced by high-frequency excitation. Furthermore, the high-frequency excitation in the stream direction leads to a significant amplification between the 

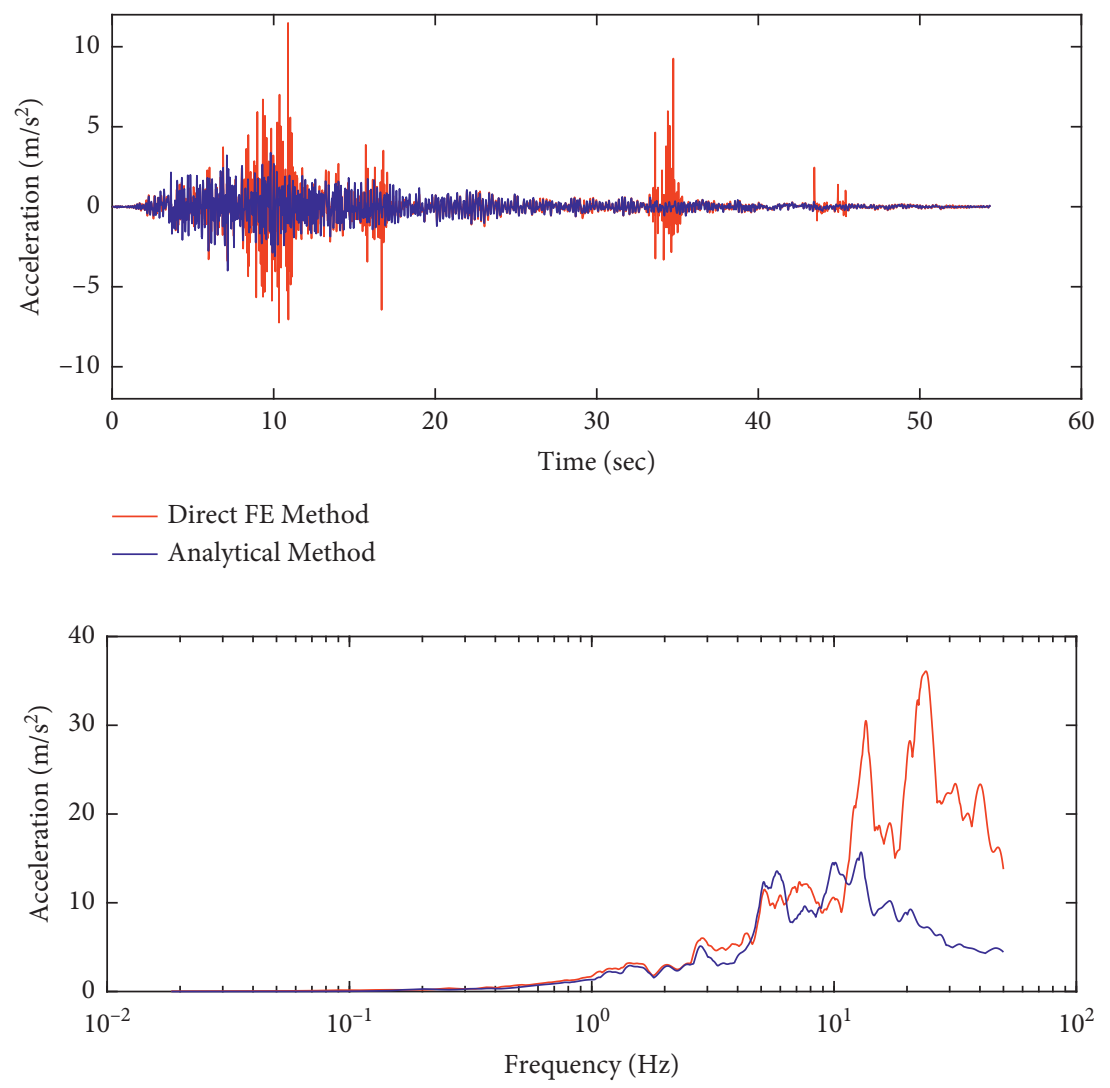

FIGURE 17: Acceleration time history and corresponding response spectrum induced by the Taft earthquake for a middle point at the dam crest in the cross-stream direction.

crest and the cross-sectional change. The amplification of the accelerations between the crest and the heel increases from the monoliths in the middle of the canyon to the monoliths next to the abutments, as shown in Figures 11 and 14. For the high-frequency excitation, there is up to 25 times and 90 times amplification in the direction of the stream and across the stream for the monoliths near the abutments, respectively. For the low-frequency excitation, they are 13 times and 12 times in the direction of the stream and cross stream, respectively. Amplifications due to the high-frequency excitation are higher than the low-frequency excitation.

7.5. Sensitivity of the Buttress Dam to Cross-Stream Vibrations. The sensitivity of the buttress dam due to the cross-stream excitation is investigated by comparing the dam responses of a model subjected only to vibrations in the stream direction and a model considering all components of the earthquake. Figure 20 shows the maximum envelope of the maximum principal stresses at upstream and downstream of the dam induced by the Swedish design earthquake, considering only the motion in the direction of the stream. The figure shows that the monoliths in the middle of the canyon have the higher stresses between 1.0 and 1.2 $\mathrm{MPa}$. The uneven stress distribution between the monoliths is related to the uneven amplification of the high-frequency excitation at the foundation surface caused by the irregular topography, as shown in Figure 9. Two monoliths adjacent to the abutments also show a local stress concentration at the cross-section change, with the highest value between 1.4 and $1.6 \mathrm{MPa}$. This may be due to the large variations in displacements within the two lateral monoliths between the cross-section change and the crest, as shown in Figure 21.

When the cross-stream excitations are included, the stresses in the monoliths increase and the stress distribution becomes asymmetric, as shown in Figure 22. Maximum stresses between 1.4 and $1.6 \mathrm{MPa}$ were generated in the monoliths. Two monoliths on the right side of the central monolith have higher stresses than the other two monoliths on the left side. This is because the PGA distribution in the cross-stream direction was not symmetrical and the PGA increased from the centre to the coordinate of $+17 \mathrm{~m}$, which includes the two monoliths next to the central monolith.

For a model exposed only to the stream vibrations of the Taft earthquake, the stress distribution is symmetrical and except for two lateral monoliths adjacent to the rock, all have almost the same stress level with a maximum of almost $0.8 \mathrm{MPa}$ (Figure 23). The reason for this is the uniform distribution of the PGA in the canyon, in the direction of the stream, as can be seen in Figure 10.

When including the cross-stream motions, the stresses in the monoliths increase and reach a maximum between 1.0 and 1.4 MPa, as shown in Figure 24. Therefore, the inclusion of cross-stream vibrations leads to an increase in stresses for both excitations, and the high-frequency excitation was higher than the low-frequency excitation. In addition, the inclusion of crossstream vibrations leads to an opening of the joints, which 

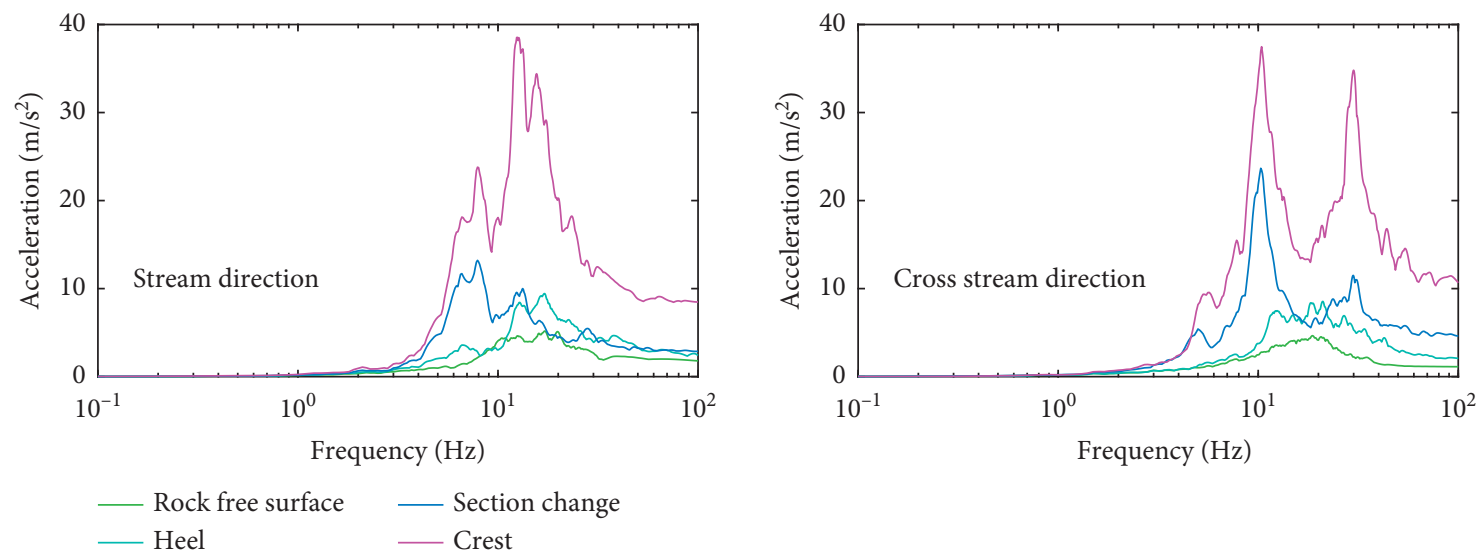

FIGURE 18: Response spectrum of acceleration time histories produced by the Swedish design earthquake at the middle of heel, section change, and crest of the dam in the (a) stream and (b) cross-stream direction with rock foundation modelling using the direct FE method.
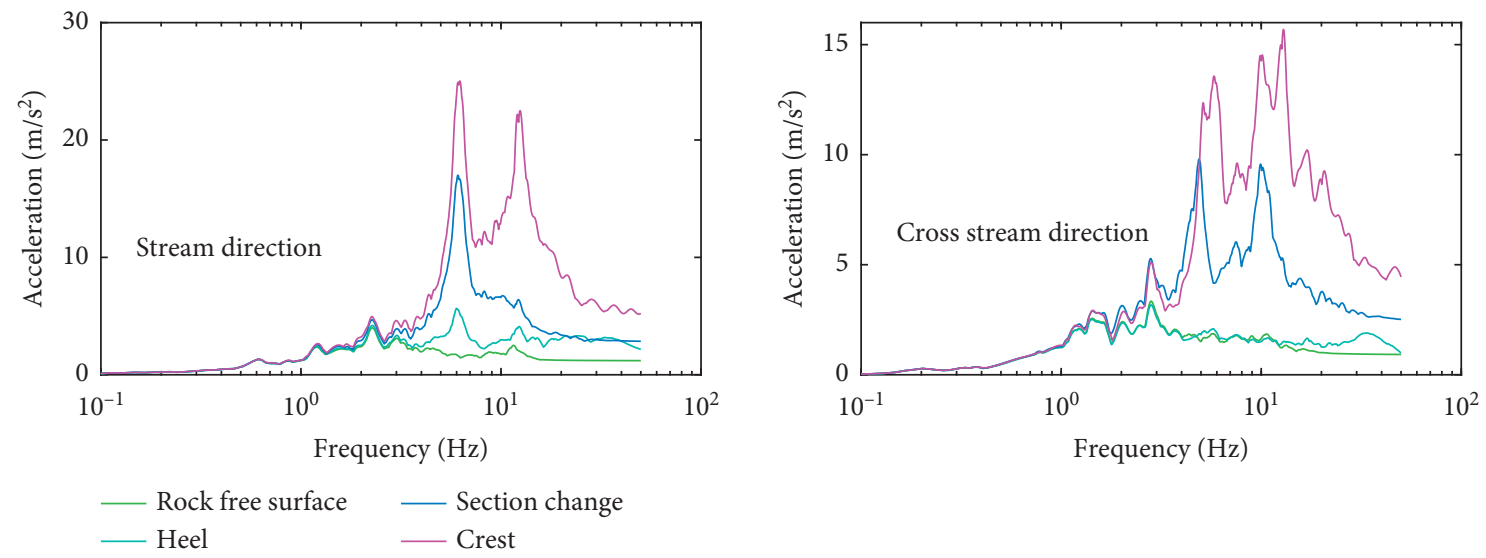

FIGURE 19: Response spectrum of acceleration time histories produced by Taft earthquake at the middle of heel, section change, and crest of the dam in the (a) stream and (b) cross-stream direction with rock foundation modelling using the analytical method.

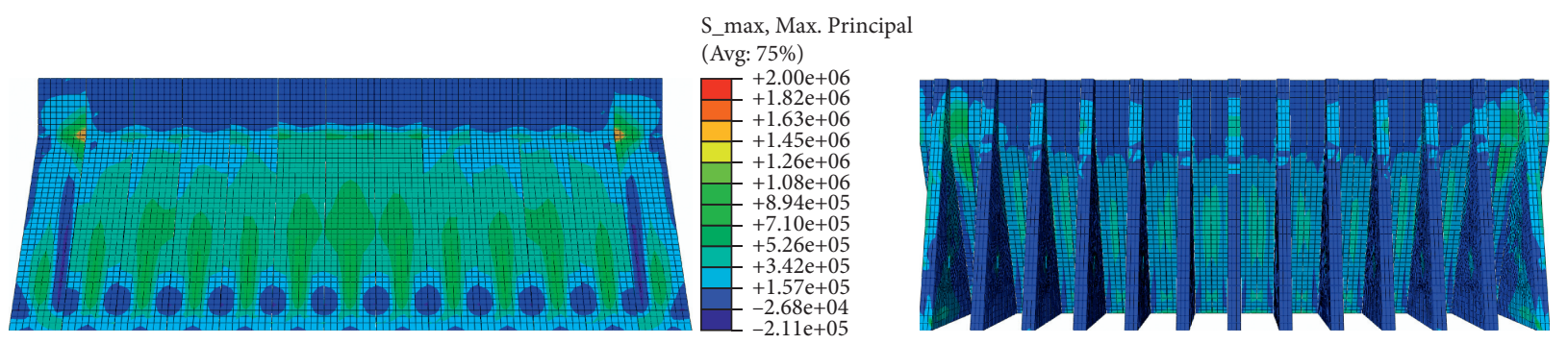

FiguRe 20: Maximum envelope of maximum principal stresses at upstream and downstream of buttress dam induced by the Swedish design earthquake considering only stream motion.

significantly reduces safety in the case of strong seismic excitations, as shown in Figures 13 and 15. The seismic excitations considered here did not lead to high stresses that could cause cracks in the concrete, so the nonlinear concrete behaviour was not considered in the analyses. However, the irregular topography of the foundation surface had a significant influence on the amplification of the rock surface motion and thus on the response of the dam. It can be seen that the high-frequency excitation produces an uneven stress distribution between the monoliths compared to the low-frequency excitation. Therefore, it is important to consider the cross-stream vibrations taking into account the topographical amplifications of the foundation surface with the effective foundation modelling method. This has also been shown to have a significant impact on the calculation of the joints' opening. As can be seen in Figures 13 and 15 , the massless method, where the topographical amplifications are not taken into account, and the analytical method, where the motion of the foundation surface is calculated with a simplification in the free-field modelling, lead to unreliable joints opening. 


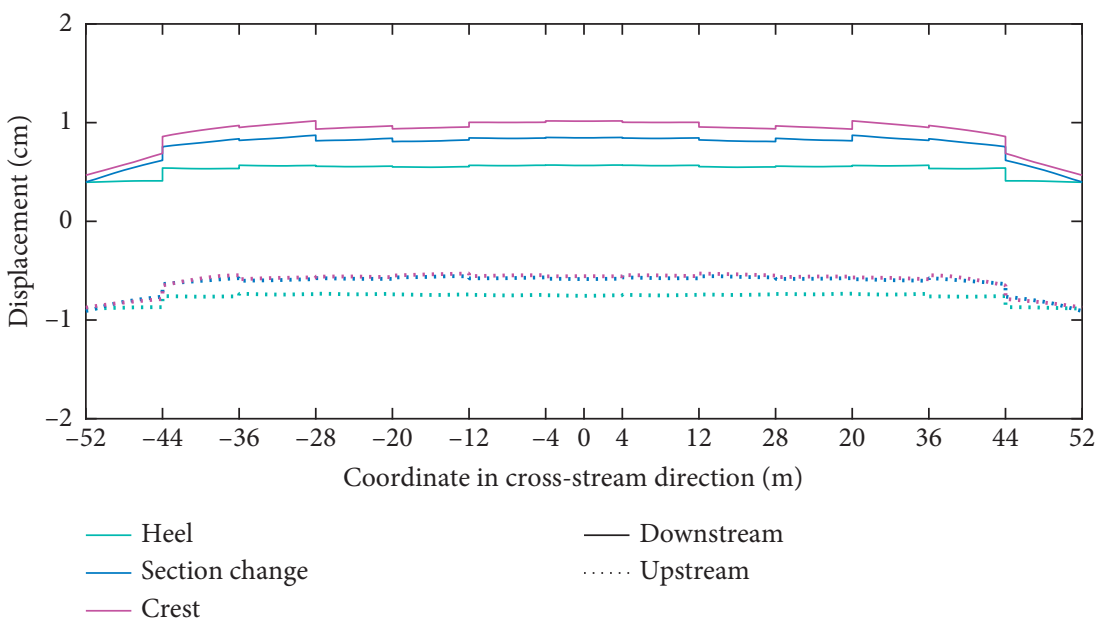

Figure 21: Maximum envelope of displacement in the stream direction induced by the Swedish design earthquake with only stream vibration.

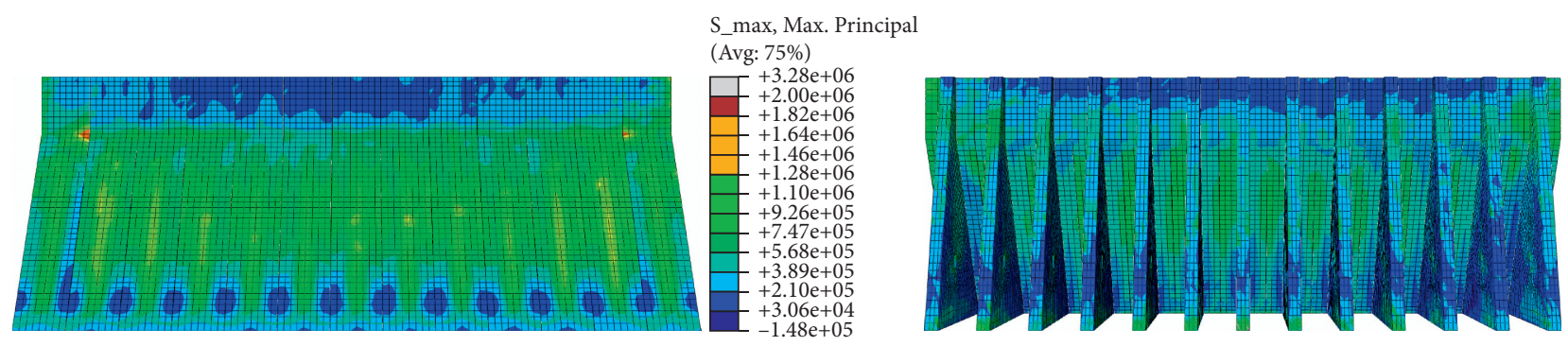

Figure 22: Maximum envelope of maximum principal stresses at upstream and downstream sides of the buttress dam with all components of the Swedish design earthquake considered.

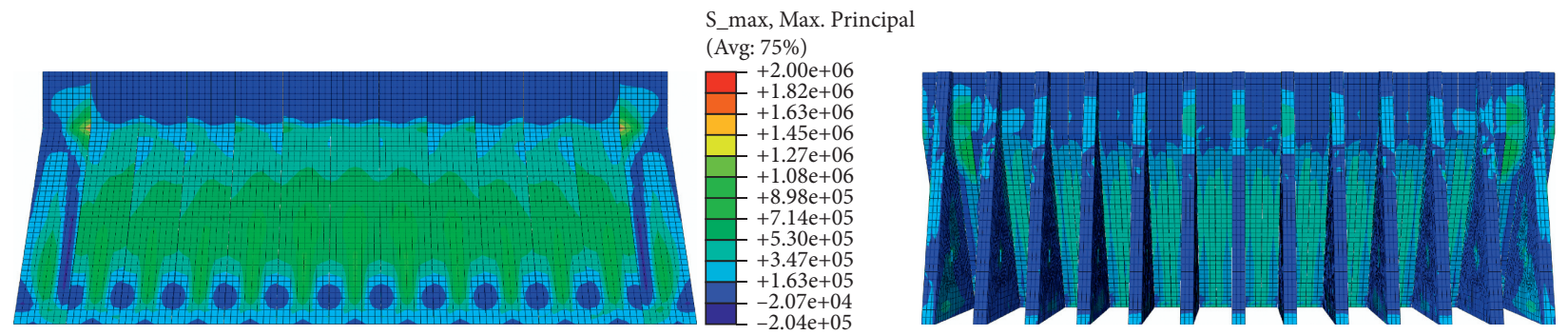

FIGURE 23: Maximum envelope of maximum principal stresses at upstream and downstream of buttress dam induced by the Taft earthquake considering only stream motion.

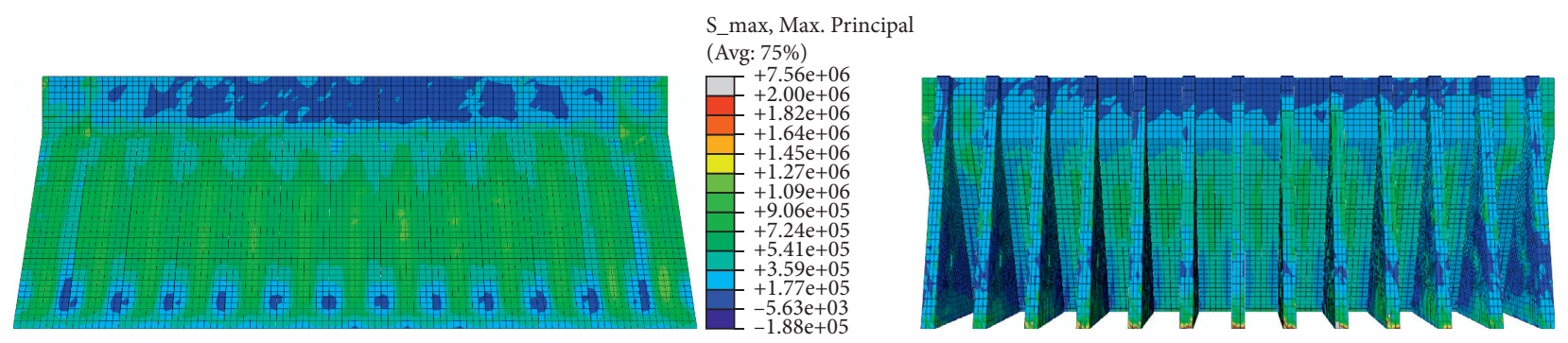

FIGURE 24: Maximum envelope of maximum principal stresses at upstream and downstream of the buttress dam considering all components of the Taft earthquake. 


\section{Conclusions}

The aim of this work was to investigate the nonlinear behaviour of concrete buttress dams subjected to high-frequency seismic excitation. For comparison, the effects of a low-frequency earthquake were also considered. The results of the eigenvalue analysis showed that a typical buttress has relatively high natural frequencies of over $6 \mathrm{~Hz}$. Higher lateral bending modes had natural frequencies above $10 \mathrm{~Hz}$ due to the slenderness of the concrete buttresses. The importance of free-field modelling of the foundation for high excitations was investigated by sensitivity analysis of the response with respect to different foundation modelling methods. Three methods were used to model the foundation: a massless approach, an effective earthquake input method using the direct finite element method, and an analytical method based on one-dimensional wave propagation theory. A new time-domain deconvolution method was developed for both shear and pressure wave propagation based on an iterative procedure using a one-dimensional $\mathrm{FE}$ column to transform the earthquake motion from the foundation surface to the corresponding input motion at depth. The following conclusions can be drawn from the analyses for the free rock motion and the dam response.

Modelling the foundation with the direct FE method and the analytical method resulted in uneven motions of the free rock surface, while the massless method resulted in uniform motions. For both excitations, the discrepancy between the analytical and the direct FE method was insignificant. Only at the low frequencies in the cross-stream direction did the analytical method slightly underestimate the motion. The irregular surface topography had a significant influence on the amplification of the high-frequency seismic waves. The free surface motion caused by the high-frequency excitation showed significant acceleration variation compared to the low-frequency excitation. This led to large differences between the massless method and a method that accurately accounts for the topographic amplifications of the seismic waves.

For the dam response, the massless method leads to unreliable results, especially for high-frequency excitations. The massless method gave a sliding failure of the dam for high-frequency excitation, but for low-frequency excitation in the stream direction it overestimated the accelerations and underestimated the joint opening in the cross-stream direction. The analytical approach behaved similarly to the direct FE method in the stream direction. In the crossstream direction, the joint opening could be overestimated or underestimated when using the analytical approach compared to the direct FE approach. This is particularly important for low-frequency excitations. Therefore, it is important to use an accurate modelling approach for the rock foundation, especially in cases where nonlinearity is considered.

A comparison between the dynamic responses of the buttress dam due to high-and low-frequency motions showed that high-frequency motions excited free vibration frequencies above $10 \mathrm{~Hz}$, while the low-frequency motion affected free vibration modes up to $13 \mathrm{~Hz}$, for the earthquake cases studied here. This shows that the buttress has higher natural frequencies due to its slenderness, which are more sensitive to high-frequency excitations. Therefore, the stresses in the monoliths were higher for the high-frequency excitation than for the low frequencies. Due to the topographic amplifications of the seismic waves at the canyon surface, the high-frequency excitation leads to a nonuniform stress distribution between the monoliths compared to the low-frequency excitation. Allowing for cross-stream vibration caused joints to open and stresses in the dam to increase, reducing the safety of the dam, especially during high-frequency excitation.

\section{Data Availability}

The data used to support the findings of this study are available from the corresponding author upon request.

\section{Conflicts of Interest}

The authors declare no conflicts of interest.

\section{References}

[1] C. Shen, H. Chen, C. Chang et al., "Earthquake induced by reservoir impounding and their effect on Hsinfengkiang dam," Scientia Sinica, vol. 17, no. 2, pp. 239-272, 1974.

[2] M. Ahmadi, G. Khoshrang, A. Mokhtarzadeh, and A. Jalalzadeh, "Behavior of a large concrete dam to an actual maximum credible earthquake," in Proceedings of the 10th world conference on earthquake engineering, vol. 7, pp. 3995-4000, Madrid, Spain, July 1992.

[3] A. R. Ghaemmaghami and M. Ghaemian, "Experimental seismic investigation of sefid-rud concrete buttress dam model on shaking table," Earthquake Engineering \& Structural Dynamics, vol. 37, no. 5, pp. 809-823, 2008.

[4] C. Ilinca, R. Vârvorea, and A. Popovici, "Influence of dynamic analysis methods on seismic response of a buttress dam," Mathematical Modelling in Civil Engineering, vol. 10, no. 3, pp. 12-26, 2014.

[5] M. A. Hariri-Ardebili and S. M. Seyed-Kolbadi, "Seismic cracking and instability of concrete dams: smeared crack approach," Engineering Failure Analysis, vol. 52, pp. 45-60, 2015.

[6] M. Colombo, M. Domaneschi, A. Ghisi, and S. Griffini, "Bearable maximum seismic action for existing concrete dams," Ingegneria Sismica-International Journal of Earthquake Engineering, vol. 35, pp. 3-24, 2018.

[7] M. Colombo, M. Domaneschi, and A. Ghisi, "Existing concrete dams: loads definition and finite element models validation," Structural Monitoring and Maintenance, vol. 3, no. 2, pp. 129-144, 2016.

[8] M. Colombo, M. Domaneschi, A. Ghisi et al., "Stress verifications of large concrete existing dams: comparison of two seismic Italian codes," Ingegneria Sismica-International Journal of Earthquake Engineering, vol. 34, pp. 61-82, 2017.

[9] W. Chi-fai, H. Jason, R. Andrew, and S. John, "Oberon dam-failure hazard of a buttress dam and its vulnerability to earthquake damage," in Proceedings of the ANCOLD (Australian National Committee on Large Dams), Conference, Perth, Western Australia, October 2012.

[10] R. W. Clough, "Non-linear mechanisms in the seismic response of arch dams," in Proceedings of the International 
Research Conference Earthquake Engineering, pp. 669-684, Skopje, Yugoslavia, June 1980.

[11] A. K. Chopra, "Earthquake analysis of arch dams: factors to be considered," Journal of Structural Engineering, vol. 138, no. 2, pp. 205-214, 2012.

[12] J. Bielak, K. Loukakis, Y. Hisada, and C. Yoshimura, "Domain reduction method for three-dimensional earthquake modeling in localized regions, Part I: theory," Bulletin of the Seismological Society of America, vol. 93, no. 2, pp. 817-824, 2003.

[13] U. Basu, Perfectly matched layers for acoustic and elastic waves: theory, finite-element implementation and application to earthquake analysis of dam-water-foundation rock systems, PhD Thesis, University of California, Berkeley, CA, USA, 2004.

[14] W. Zhang, E. E. Seylabi, and E. Taciroglu, "An ABAQUS toolbox for soil-structure interaction analysis," Computers and Geotechnics, vol. 114, Article ID 103143, 2019.

[15] Livermore Software Technology Corporation (LSTC), LSDYNA Keyword User's Manual, Livermore Software Technology Corporation (LSTC), Livermore, CA, USA, 2017.

[16] A. Løkke and A. K. Chopra, "Direct-finite-element method for nonlinear earthquake analysis of concrete dams including dam-water-foundation rock interaction," PEER Report No. 2019/02, Pacific Earthquake Engineering Research Center, University of California, Berkeley, CA, USA, 2019.

[17] Z. Chuhan, P. Jianwen, and W. Jinting, "Influence of seismic input mechanisms and radiation damping on arch dam response," Soil Dynamics and Earthquake Engineering, vol. 29, no. 9, pp. 1282-1293, 2009.

[18] D.-H. Chen, C.-B. Du, J.-W. Yuan, and Y.-W. Hong, “An investigation into the influence of damping on the earthquake response analysis of a high arch dam," Journal of Earthquake Engineering, vol. 16, no. 3, pp. 329-349, 2012.

[19] P. Jianwen, X. Yanjie, J. Feng, and W. Jinting, "Seismic stability assessment of an arch dam-foundation system," Earthquake Engineering and Engineering Vibration, vol. 14, pp. 517-526, 2015.

[20] Z. Song, F. Wang, Y. Liu, and C. Su, "Infinite element staticdynamic unified artificial boundary," Shock and Vibration, vol. 2018, Article ID 7828267, 14 pages, 2018.

[21] H. M. Westergaard, "Water pressures on dams during earthquakes," Transactions of the American Society of Civil Engineers, vol. 98, no. 2, pp. 418-433, 1933.

[22] C. Zangar, Hydrodynamic Pressures on Dams Due to Horizontal Earthquake Effects, Engineering Monograph, Denver, CO, USA, 1952.

[23] A. K. Chopra, Earthquake Analysis of Concrete Dams: Factors to Be Considered, Tenth U.S. National Conference on Earthquake Engineering, Anchorage, Alaska, 2014.

[24] A. Løkke and A. K. Chopra, "Direct finite element method for nonlinear earthquake analysis of concrete dams: simplification, modelling, and practical application," Earthquake Engineering \& Structural Dynamics, vol. 48, pp. 818-842, 2019.

[25] H. Mohammadnezhad, M. Ghaemian, and A. Noorzad, "Seismic analysis of dam-foundation-reservoir system including the effects of foundation mass and radiation damping," Earthquake Engineering and Engineering Vibration, vol. 18, no. 1, pp. 203-218, 2019.

[26] J. W. Salamon, C. Wood, M. A. Hariri-Ardebili, R. Malm, and G. Faggiani, "Seismic analysis of pine flat concrete dam: formulation and synthesis of results," in Proceedings of the Numerical Analysis, 15th ICOLD International Benchmark Workshop, G. Bolzon, D. Sterpi, G. Mazzá, and A. Frigerio, Eds., pp. 3-97, Springer, Milan, Italy, September 2021.
[27] A. Ansell and R. Malm, "Modelling of thermally induced cracking of a buttress dam," Nordic Concrete Research, vol. 38, no. 2, pp. 69-88, 2008.

[28] B. El-Aidi and J. F. Hall, "Non-linear earthquake response of concrete gravity dams part 1: modelling," Earthquake Engineering \& Structural Dynamics, vol. 18, no. 6, pp. 837-851, 1989.

[29] J. F. Hall, "Problems encountered from the use (or misuse) of Rayleigh damping," Earthquake Engineering \& Structural Dynamics, vol. 35, no. 5, pp. 525-545, 2006.

[30] Abaqus, Abaqus ver.2020 Documentation, Abaqus, Providence, RI, USA, 2020.

[31] R. L. Kuhlemeyer and J. Lysmer, "Finite element method accuracy for wave propagation problems," Journal of the Soil Mechanics and Foundations Division, vol. 99, no. 5, pp. 421-427, 1973.

[32] J.-T. Wang, C.-H. Zhang, and F. Jin, "Nonlinear earthquake analysis of high arch dam-water-foundation rock systems," Earthquake Engineering \& Structural Dynamics, vol. 41, no. 7, pp. 1157-1176, 2012.

[33] M. Goldgruber, Nonlinear Seismic Modelling of Concrete Dams, Technical University, Graz, Austria, 2015.

[34] RIDAS, Swedish Hydropower Companies Guidelines for Dam Safety, Application Guideline 7.3 Concrete Dams (In Swedish), Swedenergy AB, Stockholm, Sweden, 2011.

[35] O. C. Zienkiewicz, N. Bicanic, and F. Q. Shen, "Earthquake input definition and the trasmitting boundary conditions," in Advances in Computational Nonlinear Mechanics, I. W. Doltsinis, Ed., Springer-Verlag, Berlin, Germany, 1989.

[36] J. Lysmer and R. L. Kulemeyer, "Finite dynamic model for infinite media," Journal of Engineering Mechanics, ASCE, vol. 95, pp. 759-877, 1969.

[37] M. Cohen and P. C. Jennings, Silent Boundary Methods for Transient Analysis. Computational Methods for Transient Analysis, T. Belytschko and T. R. J. Hughes, Eds., Elsevier, Amsterdam, Netherlands, 1983.

[38] USACE, Time-History Dynamic Analysis of Concrete Hydraulic Structures. EM 1110-6051, US Army Corps of Engineers, Washington, DC, USA, 2003.

[39] P. B. Schnabel, J. Lysmer, and H. B. Seed, "SHAKE: a computer program for earthquake response analysis of horizontally layered sites," Report No. UCB/EERC-72/12, Earthquake Engineering Research Centre, Univ. of California, Berkeley, CA, USA, 1972.

[40] Y. M. A. Hashash, D. R. Groholski, C. A. Phillips, D. Park, and M. Musgrove, DEEPSOIL User Manual and Tutorial, Version 5.0, University of Illinois, Urbana, IL, USA, 2011.

[41] SL. Kramer, Geotechnical Earthquake Engineering, PrenticeHall, Hoboken, NJ, USA, 1st edition, 1996.

[42] L. H. Mejia and E. M. Dawson, "Earthquake deconvolution for FLAC," in Proceedings of the Fourth International FLAC Symposium on Numerical Modeling in Geomechanics, Madrid, Spain, May 2006.

[43] M. Khazaei Poul and A. Zerva, "Efficient time-domain deconvolution of seismic ground motions using the equivalent-linear method for soil-structure interaction analyses," Soil Dynamics and Earthquake Engineering, vol. 112, pp. 138-151, 2018.

[44] M. Wieland, "Large dams the first structures designed systematically against earthquakes," in Proceedings of the The 14th World Conference on Earthquake Engineering, Beijing, China, October 2008.

[45] SKI Swedish Nuclear Power Inspectorate, Seismic Safety-Characterization of Seismic Ground Motions for 
Probabilistic Safety Analyses of Nuclear Facilities in Sweden, SKI Swedish Nuclear Power Inspectorate, Stockholm, Sweden, 1992.

[46] PEER, "Pacific Earthquake Engineering Research Center," 2020, http://peer.berkeley.edu/.

[47] J. J. Fry and N. Matsumoto, "Validation of dynamic analyses of dams and their equipment," Contributions to the International Symposium on the Qualification of Dynamic Analyses of Dams and Their Equipments, CRC Press, Boca raton, FL, USA, 2016.

[48] J. Enzell, R. Malm, A. Abbasiverki, and L. Ahmed, "Nonlinear behaviour of a concrete gravity dam during seismic excitation, A case study of the Pine Flat Dam," in Proceedings of the Numerical Analysis of Dams: 15th ICOLD International Benchmark Workshop, vol. 99-112, Springer Nature, Milan, Italy, September 2019.

[49] D. Chen, C. Hou, and F. Wang, "Influences on the seismic response of the gravity dam-foundation-reservoir system with different boundary and input models," Shock and Vibration, vol. 202115 pages, 2021. 